\title{
Transnational Mathematics and Movements: Shiing- shen Chern, Hua Luogeng, and the Princeton Institute for Advanced Study from World War II to the Cold War ${ }^{1}$
}

\author{
Zuoyue Wang 王作跃, ${ }^{2}$ Guo Jinhai 郭金海 3
}

(California State Polytechnic University, Pomona 91768, US; Institute for the History of Natural Sciences, Chinese Academy of Sciences, Beijing 100190, China)

\begin{abstract}
This paper reconstructs, based on American and Chinese primary sources, the visits of Chinese mathematicians Shiing-shen Chern 陈省身 (Chen Xingshen) and Hua Luogeng 华罗庚 (Loo-Keng Hua) ${ }^{4}$ to the Institute for Advanced Study in Princeton in the United States in the 1940s, especially their interactions with Oswald Veblen and Hermann Weyl, two leading mathematicians at the IAS. It argues that Chern's and Hua's motivations and choices in regard to their transnational movements between China and the US were more nuanced and multifaceted than what is presented in existing accounts, and that socio-political factors combined with professional-personal ones to shape their decisions. The paper further uses their experiences to demonstrate the importance of transnational scientific interactions for the development of science in China, the US, and elsewhere in the twentieth century.
\end{abstract}

Keywords: Shiing-shen Chern, Chen Xingshen, Hua Luogeng, Loo-Keng Hua, Institute for

1 This article was copy-edited by Charlie Zaharoff.

2 Research interests: History of science and technology in the United States, China, and transnational contexts in the twentieth century. He is currently writing a book on the history of American-educated Chinese scientists and China-US scientific relations. Email: zywang@cpp.edu 3 Research interests: History of mathematics in China, history of science and technology in modern China, and the history of the Chinese Academy of Sciences. Email: gjinhai@ihns.ac.cn 4 When they are first introduced in this paper, the names of Chinese people in English are usually given in the form of the standard Pinyin spellings, with the family names first and given names second (for example, "Hua Luogeng"). Chinese Americans who spent the majority of their careers in the US in this period usually adopted the traditional Wade-Giles spellings of their names; when introducing these individuals, Wade-Giles spellings are given, followed by Pinyin spellings in parentheses. Chern, who belonged to this category, actually modified the Wade-Giles spelling of his name into "Shiing-shen Chern" (or Shiing-Shen Chern or S. S. Chern), which is used in this paper. Original names in quotes will not be changed. In most cases we provide the Chinese characters of Chinese names when they are first introduced. We also use Pinyin spellings for the names of places and institutions, with the exceptions of Tsinghua, which continues to use its traditional Wade-Giles spelling. 
Advanced Study, Princeton, Oswald Veblen, Hermann Weyl, J. Robert Oppenheimer, mathematics, transnational science, China, United States, World War II, Cold War

\begin{abstract}
摘 要: 本文根据中美史料重建中国数学家陈省身和华罗庚在 20 世纪 40 年代访问美国 普林斯顿高等研究院的经过, 尤其是他们与该院两位著名数学家维布伦 (Oswald Veblen) 和外尔 (Hermann Weyl) 的交往。文章提出, 陈省身和华罗庚在中美之间进行跨国迁移 时, 他们的动机和选择比现有研究所呈现出来的更加复杂和多面, 而且是社会、政治因 素与个人、专业考量交织在一起的结果。文章用他们的经历来论证跨国科学交流对中国、 美国和其他地方 20 世纪科学发展的重要性。

关键词: 陈省身, 华罗庚, 普林斯顿高等研究院, 维布伦 (Oswald Veblen), 外尔 (Hermann Weyl), 奥本海默 (J. Robert Oppenheimer), 数学, 跨国科学, 中国, 美国, 第二次世 界大战, 冷战
\end{abstract}

\title{
1 Introduction
}

\} n early January 1949, J. Robert Oppenheimer, the theoretical physicist who had served as director of the Institute for Advanced Study (IAS) in Princeton, New Jersey, since 1947, received an eagerly awaited letter. It was from Shiing-shen Chern 陈省身 (Chen Xingshen, 1911-2004) and dated January 2: "I am glad to inform you that I arrived last night in San Francisco, with my family." 5 Oppenheimer must have breathed a sigh of relief at bringing Chern, a brilliant Chinese mathematician who had visited the IAS from 1943-1946, back to the US. On October 1, 1949, the Chinese communist leader Mao Zedong 毛泽东 (1893-1976) would declare the founding of the People's Republic in Beijing. Two months later, the United States-backed Nationalist government under Jiang Jieshi 蒋介石 (Chiang Kai-shek, 1887-1975), together with the Institute of Mathematics of the Academia Sinica, of which Chern had been acting director, would flee to Taiwan Province.

Almost exactly a year after Chern's letter to Oppenheimer, the IAS received another note in the mail that carried equally sensational news. This time it was from Hua Luogeng 华罗庚 (Loo-Keng Hua, 1910-1985), who, like Chern, was an outstanding Chinese mathematician who had visited the IAS from 1946 to 1948 and had taught thereafter at the University of Illinois, Urbana. In the letter, Hua announced that he was moving in the opposite direction: from the United States back to China, which in the burgeoning Cold War meant crossing the "Iron Curtain," as China was now aligned with the Soviet Union. Dated January 15, 1950, and addressed to Gwen Blake, secretary of the IAS's School of Mathematics, it simply stated, "I beg to inform you that my

5 S. S. Chern to J. Robert Oppenheimer, January 2, 1949, Director's Office Records, Member Files, Box 20, Folder "Chern, Shiing-shen," the Shelby White and Leon Levy Archives Center, Institute for Advanced Study, Princeton, NJ (hereafter Chern/DO/Mem). Also available at https://albert. ias.edu/handle/20.500.12111/2914, accessed November 2019. 


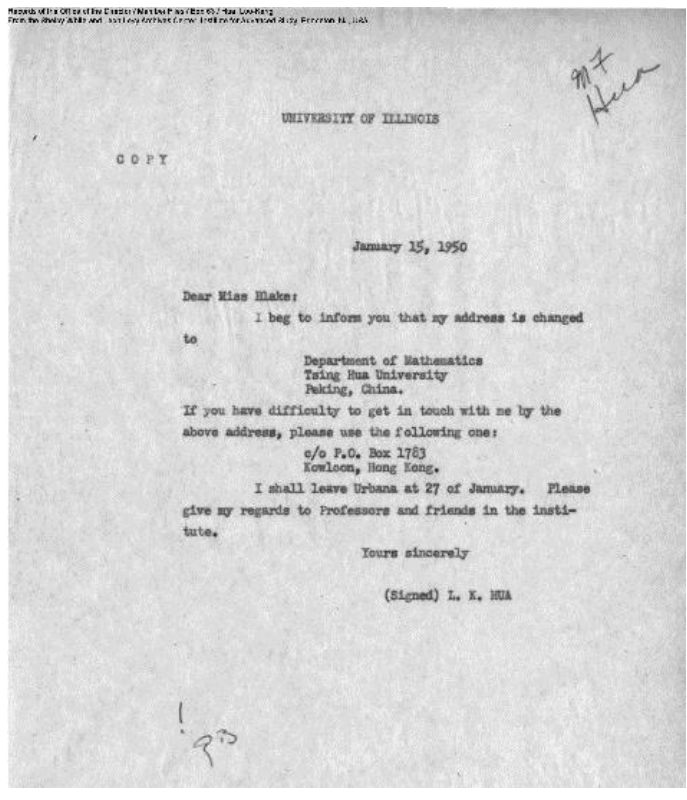

Figure 1: Loo-Keng Hua to Gwen Blake, January 15, 1950, informing her that he would move from the US back to China (Director's Office Records, Member Files, Box 63, Folder "Hua, Loo-Keng," the Shelby White and Leon Levy Archives Center, Institute for Advanced Study, Princeton, NJ). address is changed to Department of Mathematics, Tsing Hua University, Peking, China." Tsing Hua (more commonly Tsinghua or Qinghua) had been the main institutional home for both Chern and Hua in China. In sending a copy of Hua's letter to Oppenheimer's office, Blake, who had come to know and assist both men during their visits at the IAS, simply put an exclamation point on the stark letter to indicate her own surprise at this turn of events (Figure 1$){ }^{6}$

What led two of China's - and arguably among the world's-most accomplished twentieth-century mathematicians to make such dramatically different choices at this critical juncture in both the Cold War and modern Chinese history? Indeed, did Chinese politics - domestic and international - lead to their decisions, or could other factors, for example, personal-professional considerations such as their friendly rivalry, have played a part? ${ }^{7}$ More broadly, how did these mathematicians' transnational movements -including their visits to the IAS - impact scientific developments in China and the US?

Chern and Hua met each other when Chern was a graduate student and Hua an assistant at the Mathematics Department in Tsinghua from 1931 to 1934. Chern would

6 L. K. Hua to Gwen Blake, January 15, 1950, Director's Office Records, Member Files, Box 63, Folder "Hua, Loo-Keng," the Shelby White and Leon Levy Archives Center, Institute for Advanced Study, Princeton, NJ (hereafter Hua/DO/Mem). Also available at https://albert. ias.edu/handle/20.500.12111/2913, accessed November 2019. Hua's name was sometimes rendered as "Hua Lo-Keng." A few weeks earlier, Hua had written to Hermann Weyl of the IAS, "at the moment I decide to go back to China": Hua to Weyl, December 23, 1949, Director's Office Records, Faculty Files, Box 37, Folder "Weyl, Hermann Acad Sinica Fund," the Shelby White and Leon Levy Archives Center, Institute for Advanced Study, Princeton, NJ (hereafter DO/Fac/Weyl-Acad Sinica). Also available at https://albert.ias.edu/handle/20.500.12111/2873, accessed November 2019. He also reported to Oppenheimer in March 1950 that he had arrived in Hong Kong: Hua to Oppenheimer, March 3, 1950, Hua/DO/Mem.

7 On December 18, 2000, at a symposium in Beijing commemorating the ninetieth birthday of Hua Luogeng, who had died in 1985, Chern gave a speech on their friendship (Chern 2001; Chern 2002a, 93-95). On the Chern-Hua friendly rivalry, see the incidents described below and $\mathrm{Xu}$, Yuan, and Guo 2009, 212-252. 
later remember Hua in this period as being “truly mathematically talented" (他是确有 数学天才的) but “with a heightened sense of insecurity" (有高度的不安全感) (Chern 1964, 6). ${ }^{8}$ They continued their collegial interactions in Europe in 1936 while Chern was at the University of Hamburg in Germany working on his PhD and Hua was on a two-year visit at Cambridge University in England. Chern and Hua both returned to Tsinghua as professors in 1937 and 1938, respectively, and actually shared a room together for about a year when the university moved to Kunming to escape the Japanese invasion. The two parted company in 1943, when Chern made his first extended visit to the IAS (he had stopped briefly at New York and Princeton on his way back home from Europe in 1937). When Chern returned to China in 1946, they met briefly in Shanghai while Hua was on his way to visit the IAS. They would maintain contact in the US from 1949 to 1950, once Chern had moved from the IAS to the University of Chicago, which was not far from the University of Illinois, Urbana, where Hua was teaching. Chern recalled that they actually met many times and held extensive discussions about Hua's decision to return to China in this period. ${ }^{9}$

As to why Chern made his move from China to the US in 1948, he himself gave an account in an essay published in 1988 in China. In it, Chern described his decision as having been passive, prompted by an outside push from Oppenheimer at the IAS (Figure 2):

[In 1948] I was preoccupied with my work and thus did not follow current events closely. One day at the end of October I suddenly received a telegram from Robert Oppenheimer, director of the Institute for Advanced Study (the physicist who had been in charge of the making of the first atomic bomb). It said: 'If there should be any steps that you would like to have us take to facilitate your coming to this country please let us know.' [Thus] I started to read English newspapers, and realized that the situation in Nanjing would not last. The views of my friends were divided, but to me, the choice was clear, though it meant that more than two years of [my] exhaustive labor was wasted at once. My heart was filled with sorrow when departing from Nanjing. Our entire family flew from Shanghai for the US on Pan Am on December 31, 1948. (Chern [1988] 1989, 18)10

8 On Tsinghua's Mathematics Department in this period, see Guo 2019, 233-307.

9 Chern is quoted in Wang 1999a, 154. Chern said that "we all admired his patriotic passion" (大 家都佩服他的爱国热忱) (Chern 2001, 95).

10 “我因忙于工作, 未能深切了解时局的变化。10 月底有一天忽接 Institute for Advanced Study 院长 Robert Oppenheimer（即主持制造第一个原子弹的物理学家）的电报。电文说: “如果我们可 以做什么事便利你来美, 请告知。” 我开始阅读英文报纸, 才知南京局面不能久。朋友意见纷歧。何 去何从, 在我讲是很明显的。只是两年多的心血辛苦, 弃于一旦。离开南京时的情绪是悲痛的。我 们一家于 1948 年 12 月 31 日乘泛美机由上海飞美。” 


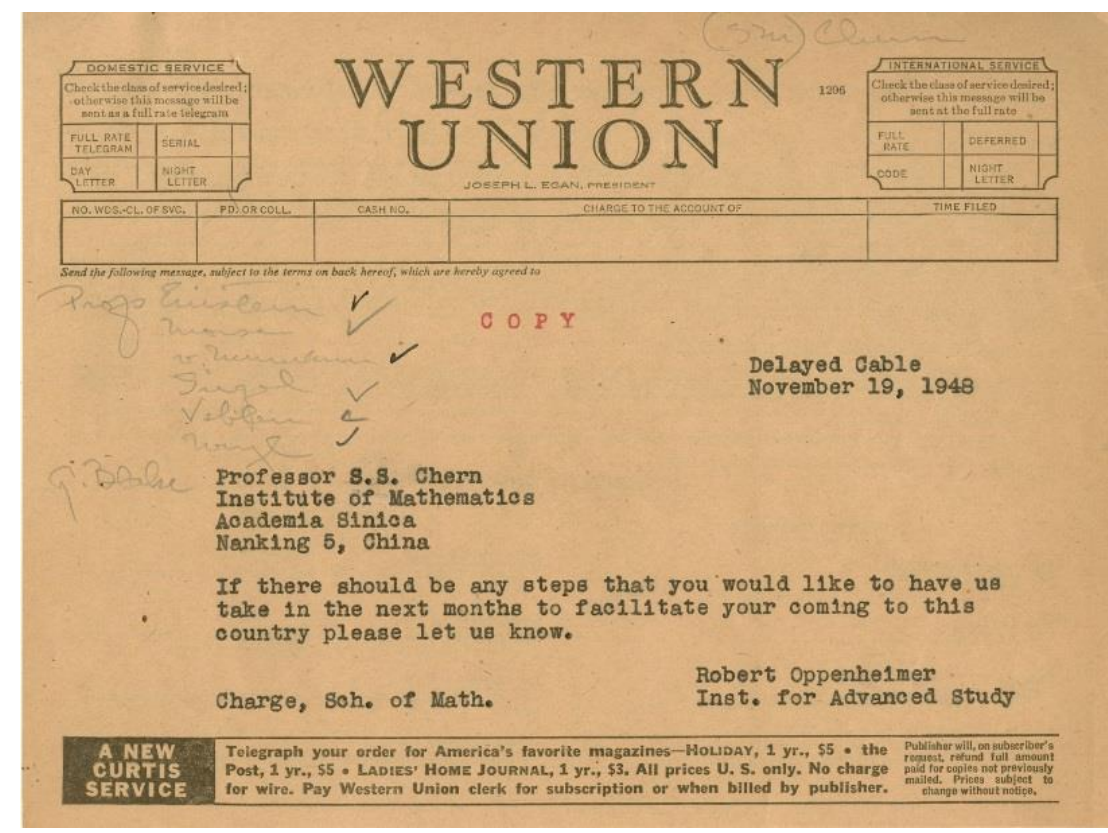

Figure 2: Telegram from IAS Director Oppenheimer to Chern on November 19, 1948.11

While mentioning the broader background of the Chinese civil war, this explanation of Chern's move to the US, which has since been adopted widely in biographical and historical studies on him and his scientific career, tends to accentuate the personal-professional considerations more than the socio-political ones. It gives the impression that it was the anticipation of the civil war's disruption of personal and professional life in Nanjing that led, almost accidentally, to the decision to migrate to the US, not a conscious political choice between the Nationalist and Communist sides in the war. Only implicitly could one sense that Chern, by moving to the US instead of the Soviet Union, was making a geopolitical statement. ${ }^{12}$

On Hua's decision to return from the US to China in 1950, the mathematician Stephen Salaff, in a 1972 biographical sketch of Hua, explained it as having been motivated by a combination of a patriotic desire to develop Chinese mathematics, sympathy with the Chinese Communist party, and resentment against "the hostility directed at patriotic Chinese in the United States" amidst McCarthyism (Salaff 1972, 153-154). In his excellent and authoritative book-length biography of Hua, Wang Yuan 王元, one of Hua's former students and himself a distinguished mathematician,

11 School of Mathematics records, Member Visitor Assistant series, Box 5, Alphabetical I (1933-1977), Chern Folder, the Shelby White and Leon Levy Archives Center, Institute for Advanced Study, Princeton, NJ.

12 See, for example, Zhang and Wang 2011, 135-136. 
indicated his agreement with Salaff by quoting him at length before adding his own assessment:

Hua's decision to return to China was based on his belief that the country had been united, that the conditions for equality and democracy had been satisfied. He very much wanted to contribute to mathematics in China for her to arrive at international level. This had been his wish for many years and he now believed that the Chinese Communist Party and the Chinese Government would lend support. Besides this, he saw the racial prejudice in the United States and the differences in cultural background. The isolationist policy being implemented against the Chinese Communist Party and all its work must also have had their effect on him. (Wang 1999a, 147-148)13

In other words, somewhat in contrast to the case of Chern, the primary driver for Hua's decision to return from the US to China was, according to Salaff and Wang Yuan, more socio-political than professional-personal, except for his desire to help China develop mathematics. Indeed, in an open letter to Chinese students still in the US that was composed by Hua on his way to China in February 1950 and broadcast by the official Chinese Xinhua Press in March, he focused on the themes of their patriotic duty to China and American racism in his call for them to follow his example and return home. ${ }^{14}$

This paper reconstructs Chern's and Hua's visits to the IAS in the 1940s and argues that their motivations and choices in regard to their transnational movements between China and the US were more nuanced and multifaceted than what is presented in existing accounts. Often, socio-political factors combined with professional-personal ones to shape their decisions, as was the case with thousands of other Chinese scientists who responded to the rapid changes around them in China and the US during World War II and the early Cold War. The availability of the remarkably well-preserved, systematic correspondence that Chern and Hua carried out with the IAS director's office and School of Mathematics, especially with two of its prominent professors,

13 Wang 1999b, on which presumably the English edition was based, has the following corresponding Chinese text (169): “华罗庚非常坚决地要回归中国的原因是他确信中国巳经统一了, 中国有了和平民主建国的条件, 他要为中国的数学赶上世界水平作出贡献。这是他多年的理想, 他 相信他的愿望会得到中国共产党与中国政府的支待的。另外, 美国社会中存在的种族岐视, 不同的 文化背景带来的孤独及中国共产党对他所作的工作, 也有一定影响。” While the first three sentences in the English translation are fairly faithful to the original text, the last two are not, which correspond to the last sentence in the Chinese text above and can be directly translated as: "Other factors that had a certain influence on him included the racial prejudice in the United States, the feeling of loneliness due to differences in cultural background, and the persuasive work on him by the Chinese Communist Party."

14 The letter was translated into English and reprinted in Wang 1999a 150-153. Hua's letter did convince some Chinese students to return home. See, for example, Cao 1999, 173-179. In it, Cao, a biologist, wrote that reading Hua's letter helped persuade her and her physicist husband, Xiang Rensheng 向仁生, to decide to return to China in 1951 from their teaching positions in Atlanta, Georgia. 
Oswald Veblen and Hermann Weyl, has helped us to understand more fully both the contents and contexts of these mathematical exchanges. ${ }^{15}$ What emerges from this reconstruction of Chern, Hua, and the IAS is an illustration of the complex interactions of political, social, professional, and personal considerations that drive human decisions in times of dramatic change. It further demonstrates the importance of transnational scientific interactions for the development of science in China, the US, and elsewhere in the twentieth century.

\section{2 "Moving frames": Chern, Veblen, and the IAS during World War II}

Chern's first journey to the IAS took place during perhaps the most difficult period of World War II for China and the United States. The prologue to this journey started before the US had formally entered the war, with a letter, dated May 8, 1941, that he wrote to Veblen, a well-known figure in the history of differential geometry, also Chern's main area of specialty. In the letter, Chern, then a professor of mathematics at Tsinghua in Kunming, China, enclosed a paper of his entitled "The Geometry of Isotropic Surfaces" and asked Veblen to help submit it to an American journal of mathematics. Chern also asked Veblen for advice as to whether he could get a fellowship to work at the IAS for one or two years, starting in 1942.16

As part of his application, Chern attached to the letter a three-page "Short Account of My Scientific Researches," together with a list of twenty-two papers, sixteen of them already published in China and abroad, and six either submitted or completed. They covered several frontier fields of mathematics, including projective differential geometry, topological differential geometry, non-Riemannian geometry, and integral geometry. He also attached a one-page biography titled "My Academic Career": he was born in Zhejiang on October 26, 1911, studied at Nankai University from 1926 to 1930, served as an assistant at Tsinghua in Beijing (then Peiping or Beiping) from 1930 to 1931, pursued graduate study there from 1931 to 1934, worked on his doctorate at the University of Hamburg in Germany under Wilhelm Blaschke from 1934 to 1936, and then spent another year with the eminent French mathematician Élie Cartan in Paris. During rare personal tutorials with Cartan, Chern came to understand the master

15 On the movements of Chinese scientists in the US in the 1950s, see Wang 2010. For a broader survey of Chinese mathematical relations with the US, including some coverage of Chern's and Hua's stays at the IAS, see Zhang and Dauben 1994; Xu 2002.

16 S. S. Chern to Oswald Veblen, May 8, 1941, School of Mathematics Records: Members, Visitors, Assistants, Box 5: Alphabetical files I (1933-1977): "Chern, S.S.," the Shelby White and Leon Levy Archives Center, Institute for Advanced Study, Princeton, NJ (hereafter Chern/SM/MVA I). Also available at https://albert.ias.edu/handle/20.500.12111/3413, accessed November 2019. Tsinghua was then part of the Southwest Associated University, which also included Peking University and Nankai University for the duration of WWII. Chern had communicated with Veblen since 1936-1937, when Chern was in Paris studying with Élie Cartan. See Chern 2002c, 27. 
geometer's innovative but notoriously difficult theories, especially "moving frames," and even started to extend their applications. Now a professor, he returned via the US to Tsinghua, which had to move inland in 1937 to evade the invading Japanese forces, eventually settling in Kunming. ${ }^{17}$

In his letter, Chern lamented the hardship, especially the loss of Tsinghua's library during the forced evacuation, but took pride in the truly heroic efforts that he and his colleagues made in training students and carrying out research:

With such meager equipments as you could not imagine, I have been pursuing my work for the last four years. In this period I have nevertheless achieved some results which, as my enclosed account will show, may be more significant than those done by me during my years of study in Europe. 18

He hastened to add that he would certainly like to spend one or two years at the IAS "to continue my advanced work further."19

In his response, dated June 2, 1941, Veblen was positive about both Chern's paper ("I have handed your paper ... to the editor of the Annales of Mathematics") and his desire to work at the IAS, but noncommittal about awarding a stipend beyond sending him an application form. ${ }^{20}$ Chern promptly filled out the form and returned it with not only a reiteration of his past research but also a remarkable proposal of ambitious new research in three directions: "generalization of the formula of Gauss-Bonnet," "differential geometry in the large [and] topology of homogeneous spaces," and "geometry of a space of $\mathrm{n}$ dimensions with an m-parameter family of p-dimensional varieties. . . (generalization of the geometry of paths)." 21 Nothing, however, happened for about a year afterwards.

Did Veblen not recognize Chern's talent? He did, and indeed, impressed with Chern's paper, Veblen tried to help bring him to the IAS (Figure 3). As he wrote later to Frank Aydelotte, IAS director from 1940 to 1947:

The paper [of Chern's] struck me as being extremely good, and the referee's report pronounced it first class. His work altogether seems to establish that Chern is the most promising Chinese mathematician who has thus far come to our attention. . . . [An] attempt should be made to bring him to the Institute for a couple of years. ${ }^{22}$

17 Attachments to Chern to Veblen, May 8, 1941, Chern/SM/MVA I. By then Tsinghua had joined Peking University and Nankai University to form the Southwest Associated University but both Chern and Hua mostly used Tsinghua as their institutional affiliation when they communicated with the IAS.

18 Chern to Veblen, May 8, 1941, Chern/SM/MVA I.

19 Chern to Veblen, May 8, 1941, Chern/SM/MVA I.

20 Veblen to Chern, June 2, 1941, Chern/SM/MVA I.

21 Chern to Veblen, June 28, 1941, and attachments, Chern/SM/MVA I.

22 Veblen to Frank Aydelotte, April 22, 1942, in Chern/DO/Mem. 


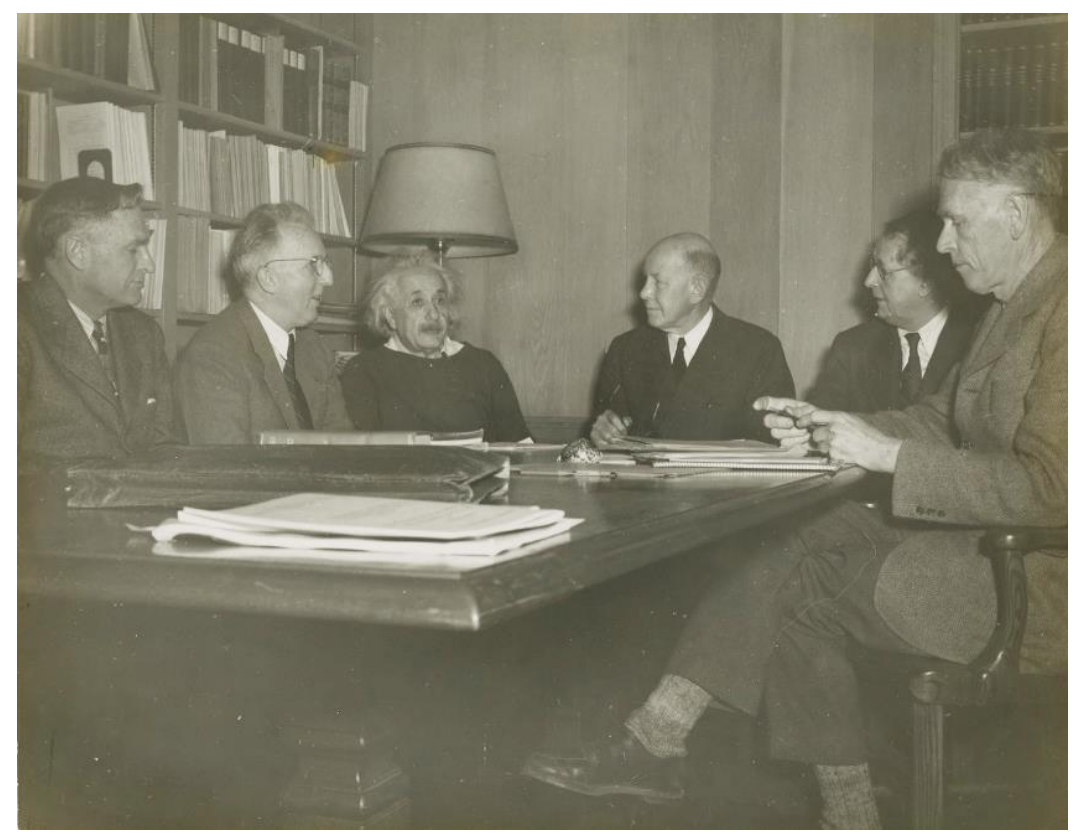

Figure 3: Institute for Advanced Study Director Frank Aydelotte meeting with faculty members of the IAS School of Mathematics in the late 1940s. From left: James Alexander, Marston Morse, Albert Einstein, Frank Aydelotte, Hermann Weyl, and Oswald Veblen. (Photographer unknown. From the Shelby White and Leon Levy Archives Center, Institute for Advanced Study, Princeton, NJ, US.)

The problem was that the IAS at that time did not have the funds to provide a stipend to Chern. Both Weyl and Veblen had been active in the American and British efforts to rescue Jewish scientists from Nazi Germany during the 1930s but their work had been hampered by financial constraints (Rider 1984). The Japanese attack on Pearl Harbor and the US entry into the war by the end of 1941 probably also played a role in the delay of action on Chern's application, as Veblen and others at the IAS started doing work for the military. By the spring of 1942, however, Veblen suggested to Aydelotte that he approach the Chinese embassy for coverage of Chern's travel expenses and a philanthropic foundation for a stipend. ${ }^{23}$ The Rockefeller Foundation agreed to sponsor the prominent European mathematicians Carl Ludwig Siegel and Kurt Gödel, who were already at the IAS, but not Chern, on the ground that the foundation "would not undertake to bring a scholar from China at this time." 24 Aydelotte next wrote to Hu Shi 胡适 (Hu Shih, 1891-1962), then the Chinese ambassador to the US, to appeal for financial support for Chern, praising him as "one of the most promising mathematicians

23 Veblen to Frank Aydelotte, April 22, 1942, Chern/DO/Mem.

24 Veblen to Aydelotte, April 8, 1942, and Frank Hanson to Aydelotte, April 30, 1942, both in Chern/DO/Mem. Hanson was associate director for the natural sciences at the Rockefeller Foundation. 
of this generation" and arguing that "his own high qualifications and the importance of the subject would seem to us to justify the Chinese government in undertaking this expense." 25 Nothing seems to have come of this overture either. ${ }^{26}$

Meanwhile, Chern, having heard nothing from the IAS for about a year, waited patiently in Kunming while continuing to make remarkable mathematical progress under difficult circumstances. On August 15, 1942, he wrote to Veblen to ask whether the IAS had made a decision on his application, recognizing that the US entry into the war might have made his hopes "difficult to be realized." He also enclosed two papers as fruits of his research in the last year. With the application of Cartan's method of equivalence, he reported happily, "the theories of Reimann spaces, Finsler Spaces, Cartan spaces, the geometry of paths, etc. all come under a unified treatment and the analytical manipulations are in many respects simpler." He added that he also "obtained some new geometries" on which he was writing a book. ${ }^{27}$ Once again, Veblen, in his reply on October 30,1942, dodged the issue of a stipend for Chern, but told Chern that he had sent his two papers, after positive reviews (and some criticisms) by the mathematician J. L. Vanderslice, to the Proceedings of the National Academy of Sciences. ${ }^{28}$

Working on and publishing mathematics remained the focus of Chern's exchanges with Veblen, but he did not give up his hope to visit the IAS. On December 12, 1942, Chern wrote Veblen to thank him for getting his papers published and then announced, "I think I shall send to your country further papers for publication." He also politely reminded Veblen of his continued interest in visiting the IAS, this time framing it as a matter not only of personal importance but also of importance to China's national scientific progress:

I am still very much interested in the present conditions in Princeton. After the Burma Road was cut half a year ago, we are practically out of contact with the outside world, and are in a sense compelled to devote our time to do research work in pure science. This is why I can still write papers on pure mathematics. If a stipend could be granted to me by the Institute for Advanced Study, I might still be able to make a trip to America, which, as I think, will be beneficial both to myself and to my fellow scientists in China. I hope you can give me some advice concerning this matter. ${ }^{29}$

Chern did not elaborate on how his IAS visit would be beneficial to other Chinese scientists, but conceivably he hoped that once abroad he could help them break

25 Aydelotte to Hu Shih, May 23, 1942, Chern/DO/Mem.

26 Lota Lois Ing to Aydelotte, May 29, 1942, Chern/DO/Mem. Ing was Hu's private secretary at the Chinese embassy then. Within four months Hu would resign his ambassadorship.

27 Chern to Veblen, August 15, 1942, Chern/SM/MVA I.

28 Veblen to Chern, October 30, 1942, Chern/SM/MVA I.

29 Chern to Veblen, December 12, 1942, Chern/SM/MVA I. 
wartime isolation and that, upon his return, he could bring new knowledge home with him along with an enhanced ability to train young scientists. In any case, Chern's persistence finally bore fruit. On February 1, 1943, Veblen wrote Chern with some good news: "I have talked with my colleagues, and we should be much pleased if you could spend a year at our Institute. I think that there is no doubt that we could obtain for you a stipend of $\$ 1,500 . " 30$ Veblen did not explain the reasons for this positive development. Perhaps the IAS financial situation improved; perhaps Chern's continued mathematical productivity pushed Veblen and the IAS School of Mathematics into action; or perhaps it was Chern's turn at the top of their list of desired visitors, now that they had secured support for Siegel and Gödel. But there was still the problem of finding sizeable funds to cover Chern's travel expenses to the US and then back to China. Probably inspired by Chern's reference to the importance of his trip to Chinese scientists, Veblen told Chern that he was contacting the US State Department and suggested that Chern do the same with the Chinese government, justifying the visit by its national and international significance:

I am making inquiries from the Division of Cultural Relations of our State Department. Perhaps you could arrange it somehow as an enterprise of the Chinese Government in promoting cultural relations with the United States. I am making the argument that it is very important for China to develop leaders in the various fields of scholarship, and for the United States to cooperate in this process. ${ }^{31}$

What happened here is an interesting case of packaging mathematics in politics: both Chern and Veblen were primarily interested in getting him to the IAS as a personal and scientific objective. But in order for it to happen logistically, they were willing to present it as a nationalist and internationalist project, highlighting its benefits for the Chinese scientific community, the development of Chinese science and the Chinese nation, and cultural relations with the US. While it was a plausible argument to make, couching Chern's visit to the IAS in such broad terms tended to mask Chern's and Veblen's professional scientific interest while at the same time anticipating a pattern common in the postwar period: linking science with nation-building and international geopolitics. ${ }^{32}$

Things moved quickly after the IAS stipend was awarded to Chern. The same day Veblen wrote to Chern, he indeed sent a letter to a contact at the US State Department, requesting assistance to cover travel expenses for Chern. In it, he argued that China

30 Veblen to Chern, February 1, 1943, Chern/SM/MVA I. Parts of this and other letters related to Chern's 1943-1946 visit to the IAS from the IAS archives have been translated into Chinese in Zhang and Wang 2011, 90-98.

31 Veblen to Chern, February 1, 1943, Chern/SM/MVA I.

32 See, for example, Krige and Barth 2006. 
needed to cultivate "a few citizens" as world leaders in scholarship, that Chern was "one of the few, and perhaps the only, Chinese whom I know who has a chance of playing this role in mathematics," and that it would be to the credit of the US if it could "contribute substantially to the development of such a man." 33 Before receiving Veblen's good news, Chern appears to have written a letter to Veblen to tell him that he had received a stipend from Tsinghua for a visit to the US. Having received and then lost the letter in late March, Veblen wrote to Chern on April 12 that in view of the Tsinghua stipend, the IAS would normally withhold its own offer but "It is clear from your letter, and I think obviously from general considerations" that a partial IAS stipend of $\$ 1,000$ (instead of the original $\$ 1,500$ ) "would be helpful." 34

On his part, Chern, having received Veblen's February 1 offer (but before the April 12 letter), wrote back on March 4 to thank Veblen for the stipend and to report that he was asking the Chinese Ministry of Education and his own university for a grant to cover his travel expenses. Failing that, he would use his university subsidy for that purpose. ${ }^{35}$ Veblen received this letter in late April and quickly wrote back to tell Chern that Aydelotte, who had consulted with $\mathrm{Hu}$ Shi, convinced him to restore the IAS stipend to the original $\$ 1,500$ as a way to support Chern more adequately. ${ }^{36}$ The IAS then also contacted the US government to gain approval for Chern to utilize an American military aircraft, which was necessary for his journey. ${ }^{37}$ Meanwhile, Chern went to Chongqing, the Chinese wartime capital, to attend sessions at the Central Training Corps directed by Jiang Jieshi himself, which focused on political indoctrination by Nationalist leaders and was required of anyone going abroad in this

33 Veblen to Willys R. Peck, February 1, 1943, Chern/SM/MVA I. Peck responded that if Chern was to come in the second half of 1943, any possible funds for him would have had to wait for the new fiscal year starting on June 30, 1943. Peck to Veblen, February 5, 1943, Chern/SM/MVA I. 34 Veblen to Chern, April 12, 1943, Chern/SM/MVA I. Two of Chern's biographers believe that the lost letter was actually Chern's letter of March 4, 1943, and that Veblen simply misremembered its contents. But letters usually took about thirty to forty days between China and the US at the time, and it was unlikely that Veblen could have received Chern's March 4 letter "two or three weeks" before April 12. It was more likely that Chern had written to Veblen that he had received Tsinghua's approval for a sabbatical leave, with stipend, in the US in 1943-1944. On Chern's sabbatical leave, see Research Office on the History of Tsinghua University 1994, 307-316. During the first year of his stay at Princeton-his sabbatical leave-Chern received about $\$ 150$ each month from his Tsinghua salary, which enabled him to pay for his return trip later. See Chern to Wu Youxun 吴有训 and Yang Wuzhi 杨武之, April 25, 1945, in Research Office on the History of Tsinghua University 1994, 311-312.

35 Chern to Veblen, March 4, 1943, Chern/SM/MVA I. Part of this letter has been translated into Chinese in Zhang and Wang 2011, 97.

36 Veblen to Chern, May 3, 1943, Chern/SM/MVA I.

37 Chern to Veblen, April 27, 1943, Veblen to Aydelotte, July 7, 1943, Aydelotte to US Military Transport Service, July 8, 1943, Aydelotte to Harvey Bundy, July 13, 1943 (Bundy was an assistant to the US secretary of war), Aydelotte to Chinese ambassador, July 19, 1943, all in Chern/SM/MVA I. 


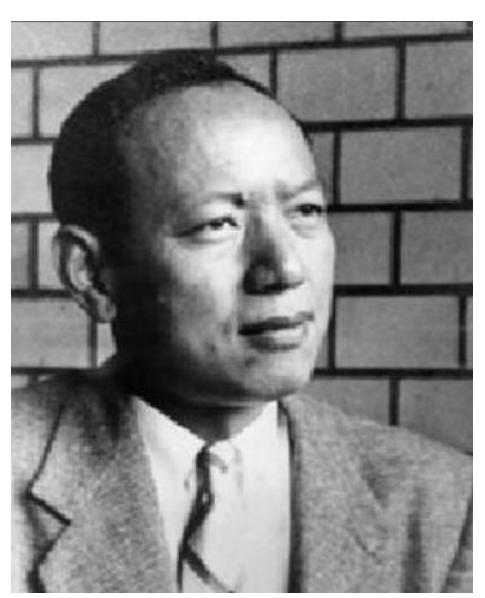

Figure 4: Shiing-shen Chern at the Institute for Advanced Study, Princeton. 41

period. ${ }^{38}$ Finally, on July 15, 1943, Chern flew from Kunming to Calcutta, where he stayed for two weeks and gave four lectures at the University of Calcutta. He then traveled to Karachi on August 1, where on August 5 he started the last part of his journey, flying free of charge (because he held a Chinese official passport) on US army planes to Florida via Africa and the Atlantic. ${ }^{39}$

Finally, on August 11, 1943, Chern landed in Miami and was admitted to the US as a Chinese government official, which entitled him to remain in the country indefinitely. He reported at the IAS about a week later and immediately set out to work (Figure 4$){ }^{40}$

In April 1944, Chern's IAS membership was renewed for 1944-1945 with the same stipend, $\$ 1,500.42$ Then, in March 1945, Aydelotte wrote to Chern to renew his stay for a third year with his stipend raised to $\$ 1,800$, noting "fine reports of the work you are doing" and praising the Chinese government for allowing Chinese scholars like Chern such opportunities in the US during the war "so as to be prepared to revive the universities in the most effective way as soon as the war is over." 43

Chern did more than just prepare to revive Chinese science and scholarship while at the IAS-he made innovations in mathematics that would reshape the field and his own life. Interestingly, Chern made these innovations partly by playing and capitalizing on his role as a Chinese transnational agent, helping to bridge gaps between mathematics as it was practiced in the US and in Europe at that time. For example, Weyl, who was then probably the most outstanding mathematician in the IAS School of Mathematics and who had originally come from Europe, tried but could not understand Cartan's new theories until Chern explained them to him. ${ }^{44}$ In return, close personal interactions with Weyl and especially with another brilliant European émigré

38 Chern's attendance at the Corps is recorded in the diaries of Zhu Kezhen 竺可桢 (Coching Chu, 1890-1974), then president of Zhejiang University, on April 11, May 2, and May 10 (Zhu 2006, 543, 557, 562).

39 Chern to Mei Yiqi 梅貽琦 (Yi-chi Mei, Tsinghua president), August 25, 1943, (Research Office on the History of Tsinghua University 1994, 309-310). It is also reprinted in Zhang and Wang 2011, 99-101. In this letter, Chern did not specify whether he flew on a commercial or US military plane from Kunming to Calcutta. In later recollections he said it was the latter for the entire trip but did not say whether the flight from Kunming to Calcutta was free. See Chern 2002c, 27-28.

40 Chern's registration form, August 18, 1943, and Francis J. H. Dever (of the Immigration and Naturalization Service) to Marie C. Eichelser, August 29, 1944, Chern/SM/MVA I.

41 Accessed November 2019. http:/ / zalafilms.com/takingthelongviewfilm/synopsis.html.

42 Aydelotte to Chern, April 4, 1944, in Chern/DO/Mem.

43 Aydelotte to Chern, March 17, 1945, in Chern/DO/Mem.

44 Interview with Phillip A. Griffith (Csicsery 2010). 
mathematician, André Weil, then at nearby Lehigh University, helped Chern carry out the bold program he had outlined to Veblen back in June 1941. Chern focused in particular on the "generalization of the formula of Gauss-Bennet," a topic on which both Weyl and Weil had made crucial contributions. They had both also refereed papers that Chern had sent to Veblen and were uniquely appreciative of his mathematical talents (Chern 1996, 54; Weil 1996, 72-73).

Within about three months of arriving at the IAS in August 1943, and stimulated by his discussions with Weil, Chern would complete his first monumental paper and have it published triumphantly under the title "A Simple Intrinsic Proof of the Gauss-Bonnet Formula for Closed Riemannian Manifolds" in Annals of Mathematics (Chern 1944b). ${ }^{45}$ In it, he not only provided a superior proof of the important theorem, which derived naturally in part from his deployment of Cartan's moving frames, but also opened new directions in the field, such as the study of fiber bundles. The proof had the virtue of "clarifying the subject once and for all," in Weil's words (Weil 1996, 74; Palais and Terng 1996, 46; Wu 2007, 99-100). "I still consider this my best piece of work," Chern would later comment (Chern 1996, 54; Jackson 1998). In addition, in working out his proof Chern discovered the existence of what was later called "characteristic Chern classes," now powerful tools in the study of fiber bundles and a foundational concept in differential geometry and mathematics in general (Chern 1944a). ${ }^{46}$ These two achievements formed one of the turning points in the development of modern differential geometry.

Both scientifically and personally, the visit to the IAS marked a highlight in Chern's life. "The surroundings and pace were most agreeable to me," he wrote later; "I reached greater maturity in my mathematical outlook and I enjoyed the stay greatly" (Chern 1996, 10). But the end of the war in summer 1945 led him to return home in early 1946. Both socio-political and personal-professional factors likely drove him to do so: peace finally seemed to have returned to China (the civil war between the Nationalists and Communists had not heated up yet), he was needed back both at Tsinghua and as the newly designated acting director of a new Institute of Mathematics of the Academia Sinica, and perhaps most importantly, he looked forward to reunifying with his family, including his wife and a six-year-old son whom he had never seen (Zhang and Wang 2011, 113-134). He left Princeton on December 18, 1945, for San Francisco but did not get on a boat for Shanghai until late February 1946. As he wrote to Gwen Blake back at the IAS School of Mathematics on February 24, 1946, from California, he was already filled with nostalgia:

45 The paper was received on November 26, 1943. On the benefits of Chern's discussions with Weil for his work, see Wu 2005, 96.

46 The paper was received on July 13, 1944. 
At last I got news that I could sail on February 27th, as you probably already know. I am glad that I am going to join my family soon, although on the other hand I like Princeton and its people even more after I have left. The reason is probably the kind of student life I led at Princeton, and student days are always full of memories. ${ }^{47}$

By late March he reached Shanghai and reported back to Veblen and Weyl on the mixed situation in China on April 2, 1946:

It has been ten days since I arrived at Shanghai. The trip was a very pleasant one, and I am glad to say that I found my family healthy and well, in spite of the difficult years. The difficulties are however not yet over, prices being so high that one has to spend a lot of time in worrying about family economy. But I believe that we can muddle through. 48

He also briefed them on his ambitious professional plans to advance mathematics in China:

What I told you about the Institute of Mathematics of the Academia Sinica seems to materialize. To suit the present conditions its temporary site will be in Shanghai. I was asked to take care of the Institute for a certain period and shall probably be in Shanghai till the end of this year, if not longer. As in industry the most important thing at the present moment is to put everybody into work. If possible, I am also thinking of inviting some younger mathematicians to China to stir up the situation, the difficulty being the present living conditions. Any advice from you will be deeply appreciated. 49

Fulfilling in part his earlier promise to use his IAS trip to benefit other Chinese scientists, Chern started training a group of talented young Chinese mathematicians at the Institute of Mathematics at the Academia Sinica, especially in topology, and promoted US-China scientific exchanges. ${ }^{50}$ For example, in his letter dated April 2, 1946, he told Veblen and Weyl that the senior Chinese mathematician (and his former professor) Jiang Lifu 姜立夫 (Li-Fu Chiang) planned to visit the IAS in 1946-1947 with financial support from the Chinese government, and asked that they send Chiang an invitation for this purpose. He also shared the news that Hua, his Tsinghua colleague, "is now in Soviet Russia and will visit the U.S. when he comes back." 51 Soon after, he

47 Chern to Black, February 24, 1946, Chern/SM/MVA I. In the letter, Chern also asked Black for assistance in the distribution of his reprints with a long list of recipients. It should be noted that staff members at scientific institutions like the IAS, often well-educated young women, played a pivotal role in scientific communication that should draw more attention from historians.

48 Chern to Veblen and Weyl, April 2, 1946, Chern/SM/MVA I

49 Chern to Veblen and Weyl, April 2, 1946, Chern/SM/MVA I.

50 On Chern's activities in 1946-1948 in China, see Chern [1988] 1999; Tian 2000; Zhang and Wang 2011, 113-134; Guo 2006. Among Chern's trainees was Wu Wenjun 吴文俊, who became a leading mathematician in China and the world.

51 Chern to Veblen and Weyl, April 2, 1946, Chern/SM/MVA I. 
initiated the complex process of inviting Weyl to visit China for one year and even succeeded in having the Academia Sinica send $\$ 10,000$ to Weyl for this purpose. In the end, Weyl was unable to make the trip due to his wife's illness and the intensification of the civil war in China. ${ }^{52}$

\section{3 "A more eruptive type": Hua, Weyl, and IAS in the 1940s}

If Chern's first journey to the US could be described as "circuitous" due to the logistical difficulties involved in transnational travel during WWII, Hua's was even more so. From the existing record, it appears that Hua first wrote to Weyl to apply for a visit to the IAS shortly before March 15, 1943. It is not certain but likely that Hua undertook this step because he was encouraged by the recent news of Veblen's offer of a stipend to Chern (Chern had written to Veblen on March 4 to accept the offer). ${ }^{53}$ Records in the IAS archives indicate that Hua had written to Weyl at least two times before this March 15 letter. In early 1940, he had sent Weyl abstracts of two papers for presentation in absentia at a meeting of the American Mathematical Society (AMS) in Washington. ${ }^{54}$ And then, shortly before his letter of March 15, 1943, he had written a letter each to Weyl and Siegel with two recent papers attached: "On the theory of automorphic functions of the n-th order, I. Geometrical base" and " . . II -Classification of hypercircles." 55 In his March 15 letter, Hua wrote:

I was told that letters with scientific correspondence is extremely difficult for the censors and then some delay is caused. Thus it seems to be desirable to write you a letter without mentioning of math. In my previous letter, I expressed my willingness to come to Princeton to do researches under the inspiration of you and Prof. Siegel. Now I am going to describe my situation more precisely. I have a family of six members and I am in desperate condition. Thus the traveling expense (for one) is badly needed and it is better

52 See the correspondence on this matter in DO/Fac/Weyl-Acad Sinica.

53 Hua to Weyl, March 15, 1943, School of Mathematics Records: Members, Visitors, Assistants: Box 35: Alphabetical files II (1978-1983): Hua, Luogeng (in file: Loo-keng), the Shelby White and Leon Levy Archives Center, Institute for Advanced Study, Princeton, NJ (hereafter Hua/SM/MVA II). Also available at https://albert.ias.edu/handle/20.500.12111/2929, accessed November 2019. In this letter, Hua did not mention Chern.

54 Temple R. Hollcroft to Weyl, April 2, 1940, Hua/SM/MVA II. Hollcroft was the associate secretary of the AMS who thanked Weyl for transmitting Hua's abstracts to the AMS. He also wrote a letter of appreciation to Hua stating, "It is encouraging to all mathematicians to know that you are carrying on research in mathematics in the face of great difficulties." Hollcroft to Hua, April 2, 1940, Hua/SM/MVA II.

55 These two letters to Weyl and the one to Siegal are not included in the records on Hua at the IAS. Their existence is inferred from the correspondence between Hua and Weyl thereafter in Hua/SM/MVA II. 
to get a job than a fellowship. (Certainly a high-paid fellowship with travelling expense may also meet the purpose). ${ }^{56}$

Then he gave a brief account of his professional career, starting as a "Reader on Math" at Tsinghua from 1932 to 1936, then as a research fellow of the China Foundation for the Promotion of Education and Culture working at Cambridge University from 1936 to 1938, and currently as a professor of mathematics at Tsinghua. He did not mention (though it was possible that Weyl and other mathematicians) knew his legendary story, similar to that of the Indian mathematician Srinivasa Ramnujan, as a largely self-taught mathematician from a poor family in Jintan, Jiangsu. He had published a paper on mathematics in Kexue (Science 科學) of the Science Society of China and was thus "discovered" by Xiong Qinglai 熊庆来, then chairman of the mathematics department at Tsinghua. But he did mention in his letter to Weyl that he had won the "First Prize of Science of the Ministry of Education in China" in 1941.

Despite the "no math" pledge, Hua still included a page on his mathematical work (with a preface to the censor that it could be detached from the letter) listing nine areas, including additive prime-number theory (on which he had written a book that was set for publication in the Soviet Union), Tarry's problem, exponential sums, and Fourier transforms in the complex domain. ${ }^{57}$ Returning to his desire to visit the IAS, he concluded the letter with a remarkable, if rumbling, explanation on his patriotic motivations for doing so:

Finally, I should like to take this opportunity to express one of my beliefs, though my poor English prevents me to do it properly. The old country is on the way for recovery, Science is extremely needed. Thus any help to the young scientists would mean a great help of the reconstruction of the country; and any influence to the young scientists would mean an influence to the history of science in China. The aim for my intension to come to Princeton is not for the personal sake, but for my country. On the country's name, I wish to have a thorough training on Mathematics, and then to develop mathematical science in China along a right way, which seems to be a part of reconstruction. ${ }^{58}$

One could argue that here Hua pushed the theme of mathematical nationalism doing mathematics for China - further than Chern: Chern had acknowledged that his trip would be important for both himself and Chinese science, but Hua was doing it explicitly "for my country." Yet some of the language Hua used here seems to echo what Chern had written to Veblen on December 12, 1942, and Veblen's letter to Chern

56 Hua to Weyl, March 15, 1943, Hua/SM/MVA II. In contrast to Chern's mostly impeccable English letters, Hua's, while good and effective overall, sometimes had grammatical errors which, when quoted, are generally presented in their original form in this paper.

57 Hua to Weyl, March 15, 1943, Hua/SM/MVA II.

58 Hua to Weyl, March 15, 1943, Hua/SM/MVA II. 
on February 1, 1943. It is again not certain but possible that Hua had seen either or both of those letters. In any case, such a strong belief in "saving China through science" (kexue jiuguo 科学救国) was wide-spread and had driven Chinese scientists to go abroad since at least the early twentieth century, as exemplified by the Boxer indemnity fellows and leaders of the Science Society of China. ${ }^{59}$ And Hua was fairly consistent in expressing his sense of scientific nationalism throughout his career, although his evolving understanding of what it meant would diverge from Chern's. In contrast to Chern's advocacy for China to excel in mathematics in the world, Hua would insist that mathematical research should serve practical national needs. 60

Meanwhile, at Princeton, Weyl hardly needed any pleading from Hua to be convinced of his talents. He had composed a statement on Hua (and Chern) on March 24 for circulation among faculty members of the IAS School of Mathematics, including Veblen, likely before he received Hua's March 15 letter. Instead, the statement was based on Hua's track record and the papers he had sent him before the March 15 letter:

In my opinion the two outstanding Chinese mathematicians are Chern and Loo-keng Hua (National Tsing Hua University, Kunming). The latter has made a number of profound contributions to the Hardy-Littlewood-Vinogradoff line of analytic number theory, and in a manuscript which he recently sent me duplicated a considerable part of Siegel's results in his big paper on symplectic geometry. It would be of the greatest value to him to get into closer contact with Siegel; but whether or not that can be done, I consider him and not Chuan-Chih Hsiung as the best second candidate from China. ${ }^{61}$

Indeed, Weyl also went to the trouble of sending Siegel's reprints to Hua by clearing them with the American censors at the "Technical Data License Division" of the Board of Economic Warfare in New York in early April 1943.62

Reacting to Hua's application to the IAS (but before receiving his March 15 letter), Weyl wrote him on April 14 "to invite you to join us as a temporary member of the School of Mathematics during the academic year 1943-1944, and to offer you a stipend of $\$ 1,000$ for the year." Weyl went on to say that:

We realize of course that the amount offered you is not enough to finance your journey or your stay in Princeton. What we hope is that a supplementary stipend from your

59 See, for example, Wang 2002.

60 It is beyond the scope of this paper to compare and contrast Chern's and Hua's visions for Chinese mathematics in detail, but the two existing biographies of them - Zhang and Wang 2011 and Wang 1999a - have provided ample material in this regard.

61 Weyl statement, March 24, 1943, Hua/SM/MVA II. Emphases original. Chuan-Chih Hsiung 熊全治 (Xiong Quanzhi) was a Chinese mathematician then teaching at Zhejiang University (at the time in exile in Guizhou Province), but he would come to Michigan State University as a graduate student in 1946 and spend the rest of his career in the US. See Hsiung 2001, xi-ix. 62 Weyl to E. W. Fowler, April 7, 1943, and L. L. Horch to Weyl, April 8, 1943, Hua/SM/MVA II. 
Government or your University will make it possible for you to come. . . We have also invited Dr. S. S. Chern for next year, and you may wish to confer with him about the journey if you desire to come. Our whole group of mathematicians will be delighted to welcome in our midst a Chinese scholar of your distinction. 63

Weyl then expressed his hope that Hua had received his (Weyl's) earlier letter informing him that "the main body of your results had been anticipated by Siegel," and that since then he had tried to send him Siegel's reprints, adding that "it is likely, though not absolutely sure, that Professor Siegel will be at the Institute during the next year." 64

After sending out his April 14 offer, Weyl finally received Hua's March 15 letter with its description of his financial difficulties, which may have played a part in the IAS's decision to increase his stipend to $\$ 1,500$. Weyl communicated this to Hua on May 10. It is possible that Aydelotte's consultation with Hu Shi over Chern's stipend also helped make the case for an increase for Hua. To ensure prompt delivery, Weyl actually sent his May 10 letter through the Chinese embassy in Washington. ${ }^{65}$ In it, Weyl also reiterated to Hua that Part I of his paper had coincided with Siegel's published work and therefore was "impossible to publish," but Part II "seems to be new and interesting." He expected that the American Journal of Mathematics would take it if Hua consented to have Siegel and his friend Duan Xuefu 段学复 (Hsio-Fu Tuan, 1914-2005), a Chinese mathematician from Tsinghua then visiting Princeton University, make necessary changes. He ended the letter by expressing his regret that no more than $\$ 1,500$ could be offered to Hua, but reiterated his welcome. ${ }^{66}$

Weyl's May 10 letter unfortunately took three months via diplomatic channels-longer than regular mail-to reach Hua in Kunming, which caused much misunderstanding and even some resentment on Hua's part. ${ }^{67}$ On the same day (May 10), not having received Weyl's April 24 letter, with its original \$1,000 offer, Hua wrote to Weyl about his disability - an "incurable leg." 68 Then, after receiving the April 24 letter, Hua wrote on May 24 to thank Weyl and the IAS for the invitation and stipend but to announce, with regret, that "owing to several reasons the present condition makes me impossible to come." Calling himself "desperately poor," he listed three expenses involved in a visit to the IAS: (i) his family, (ii) travels, and (iii) living in Princeton. He could request some assistance from Tsinghua for his family, but since the

63 Weyl to Hua, April 14, 1943, Hua/SM/MVA II.

64 Weyl to Hua, April 14, 1943, Hua/SM/MVA II.

65 Weyl to Wei Tao-ning, May 10, 1943, and Chu Chi Lok to Weyl, May 17, 1943, Hua/SM/MVA II.

66 Weyl to Hua, May 10, 1943, Hua/SM/MVA II.

67 Hua to Weyl, August 10, 1943, Hua/SM/MVA II. Weyl later regretted using diplomatic channels to send this letter. Weyl to Hua, October 7, 1943, Hua/SM/MVA II.

68 “Extract from letter of May 10, 1943, from L. K. Hua to H. Weyl," Hua/SM/MVA II. 
offer could not even cover (iii), "to make an effort to solve (ii) seems to be premature."69 At this point he already knew that Chern had received $\$ 1,500$, which seemed unfair to him, but he did not tell Weyl that he knew. Instead, he spent the rest of his remarkable three-page letter elaborating on his mathematical track record-probably thinking that the discrepancy between his and Chern's offers was caused by an inadequate knowledge of his work - and on his vision for Chinese mathematics:

In the near future I should send you a MS. of my tract which was accepted for publication by Vinogradow [Vinogradoff] in the Academy of USSR and which is the only copy in my hand. It may be useful for the future reference of the Institute. It may be a loud speaker of my works. ${ }^{70}$

Without explicitly stating so, he hoped that a more detailed explanation of his achievements would convince the IAS to increase his stipend:

I ought to confess that I was too sentimental. As I learned Prof. Siegel is living at Princeton, I forgot all and made a request to you for coming and without giving any references of my past deed. For this reason, besides the MS. of the tract, I shall write a report of my previous results to you. If the Institute would re-consider the situation, I should be greatly delighted. ${ }^{71}$

Finally, he expressed his regret for not being able to come to the IAS under the circumstances and expanded on his vision for mathematical development in China:

I am so upset, as I find no way to come. It is my object for a long time to be a pupil of you. My attitude to mathematics is not narrow minded, and I wish to understand the most fruitful parts of mathematics from mathematical philosophy to applied mathematics. For I believe that the mathematical development in China should have a good start, too technical or too narrow minded beginning would prevent the development in the future. ${ }^{72}$

Hua's comments about the need for a broad foundation for the long-term development of mathematics in China reveal how nationalism informed his vision for China's national scientific development as well as his own. In his desire to be a part of and even a leader in the project of nation-building through science, he was not alone. In 1942, for example, Zeng Chengkui 曾呈奎 (Cheng Kwei Tseng, 1909-2005), then a Chinese phycologist (studying marine plants) at the Scripps Institution of Oceanography

69 Hua to Weyl, August 10, 1943, Hua/SM/MVA II.

70 Hua to Weyl, May 24, 1943, Hua/SM/MVA II. The letter also came with a list of Hua's papers and "An Account of Hua's Works up to 1943."

71 Hua to Weyl, May 24, 1943, Hua/SM/MVA II.

72 Hua to Weyl, May 24, 1943, Hua/SM/MVA II. 
in La Jolla, California, had made a similar argument to William R. Taylor, his skeptical former PhD mentor at the University of Michigan, about the need for him to learn (and practice) many areas of ocean study beyond phycology. They were of great importance, he wrote, "in my future career as a pioneer in Chinese marine biology" (Neushul and Wang 2000, 67-68). ${ }^{73}$ Indeed, Chern himself would soon plan to attend a symposium on applied mathematics at Brown University in the summer of 1945 in order to move out of "research in the "ivory tower'" and make mathematics useful for "national salvation," as he wrote in April 1945 to Wu Youxun 吴有训 (1897-1977), dean of the College of Sciences at Tsinghua, and Yang Wuzhi 杨武之 (1896-1973), chair of Tsinghua's Mathematics Department. ${ }^{74}$

In his letter of May 24, 1943, Hua also responded to Weyl's point about the resemblance to Siegel's work, whose reprints he had received. He conceded that the overlap was a problem for Part I of his paper but argued that Part II was distinct from Siegel's work and that he was done with Parts III and IV. Reading Siegel's paper reminded him of the devastating isolation under which he and other Chinese scientists worked at the time:

As I found that most of the references given by Prof. Siegel were not available here, I felt so [much] discomfort and disappointed. In particular Cartan's admirable paper is badly needed. Nevertheless, I shall still go on my researches, since, I believe, in the future some body will give me a fair criticism in which my circumstances will be taken into account. ${ }^{75}$

Then, on July 18, 1943, still not having received Weyl's May 10 letter, Hua sent Weyl a copy of a letter he had received from Paul Vinogradoff of the Soviet Academy of Sciences on the acceptance for publication of Hua's "excellent" book on Additive Prime Numbers. Hua added that the book had won him the First Prize of the Chinese government in 1941 and that he would "be greatly delighted" if it could be published in English in the US. ${ }^{76}$

73 Taylor had doubted that Zeng could accomplish what he wanted to do within a short time period.

74 Chern to Wu Youxun and Yang Wuzhi, April 25, 1945 (Research Office on the History of Tsinghua University 1994, 311-312, esp. on 312).

75 Hua to Weyl, August 10, 1943 (Siegel 1943). The paper Siegel 1943 was received on February 27, 1942. Cartan's paper cited by Siegel and mentioned by Hua was Cartan 1936. It is possible that this paper was among those that Chern had brought back from Cartan in 1936 or were sent to him after his return to China in 1937, and that Hua knew of Chern's access to it. If so, it is not clear whether Hua had asked Chern to borrow a copy of this paper. Understood in this context, and assuming that Hua believed that Weyl knew Chern had studied with Cartan and could have a collection of Cartan's papers, it is probably not far-fetched to construe this passage as an implied criticism of Chern, or at least a plea for understanding that Chern had an advantage over him.

76 Hua to Weyl, July 18, 1943, Hua/SM/MVA II. 
Meanwhile, Weyl received Hua's May 24 letter on July 6 and wrote back on July 30 that he regretted Hua's inability to come. He reminded him of the increased stipend, but also acknowledged that even with the latter it was still difficult for Hua to come. Nevertheless, he concluded on an optimistic note: "we shall not give up the idea of having you with us at some later time." 77 After receiving Hua's July 18 letter, another one dated July 24 forwarding a revised Part I of his paper, and his Additive Prime Numbers manuscript in English, Weyl wrote to Hua on September 27 informing him that he would submit the paper to a journal but that if he wanted his book manuscript to be published in the US, he needed to get Vinogradoff's consent. ${ }^{78}$

At long last, Hua received Weyl's May 10 letter with its increased offer of a $\$ 1,500$ stipend, to which he immediately responded. In this remarkable letter, dated August 10, 1943, Hua expressed the "great comfort" he took in the good news but also revealed, finally, how deeply his pride was hurt by the first offer when compared with Chern's:

But the first decision and the delayed arrival of the second decision made me in a very unfortunate position. To be frank, I did give up my intension to come as I heard the message in comparing with that of my fellow colleague. I was disappointed. I did not make any attempt for getting help from my government. Now the good news gave me a thread of light. ${ }^{79}$

Unfortunately, the increase was offset by rapid inflation and an unfavorable exchange rate for Hua, who lamented, "God bless me, fortune seems to be intentionally against me!" Nevertheless, buoyed by the new letter, he vowed to "try my best to reach the object for which I am longing" and asked how much he would receive if he could not come for the full academic year. ${ }^{80}$

Sensing Hua's sensitivity over being treated differently from Chern, Weyl tried to assure him of their equal standing after receiving his August 10 letter. In a reply dated October 7, Weyl told Hua that his full stipend would be waiting for him if he could come before the second half of the academic year started, adding that "Our Director, Dr. Aydelotte, will be glad to furnish you with the same documents as he did Professor Chern, and send a similar letter to the Commanding Office of the United States Military Transport Service at Cairo, Egypt, as soon as we hear that you have been definitely appointed by your government to spend a year at the Institute." He also reported that Hua's (new) Part I (presumably the original Part II) would "fairly certainly" be

77 Weyl to Hua, July 30, 1943, Hua/SM/MVA II.

78 Weyl to Hua, September 27, 1943, Hua/SM/MVA II.

79 Hua to Weyl, August 10, 1943, Hua/SM/MVA II.

80 Hua to Weyl, August. 10, 1943, Hua/SM/MVA II. 
accepted by the American Journal of Mathematics and hoped "for you to come yourself and do the proofreading!" 81

After receiving Weyl's September 27 letter (but before the arrival of his October 7 letter), Hua wrote an optimistic letter dated November 1 to inform Weyl that "tomorrow" he would travel to Chongqing, the wartime capital of China, to seek government assistance to make his IAS trip possible before the beginning of the second term. ${ }^{82}$ Even Chern felt positive enough about Hua's visit that he wrote a note to Blake in December asking, "Since the chance of his [Hua's] coming here is very large, do you think it advisable to send to the American Transport Command in Karachi, India, a letter from our Institute?" 83 On January 7, 1944, Aydelotte duly sent out such a letter and informed Hua that he had done so at the suggestion of Weyl and Chern. ${ }^{84}$

Events took a dramatic turn during Hua's trip to Chongqing, however. On January 2, 1944, he wrote to Weyl that he would not come for the 1943-1944 academic year after all and explained what happened. As part of his preparation for a trip abroad he had to spend time in the Central Training Corps in Chongqing, as did Chern:

The President [Jiang] is very kind to decorate me as one of the higher officers in the Corps. Then I met dozens of ministers and vice-ministers. They all expressed that your kind appreciation of my works would be considered as a justification of their attitude and as a recognition of the scientific standing in China.... But when I finished the work, I found that it is impossible to arrive at Princeton within the limit of "better half" which was mentioned in your letter. I was greatly disappointed. I am obliged to give up the hope to come immediately. .5

The Corps not only caused Hua to miss his Princeton trip but also led those in charge of Chinese military research and development to take note of his talents. These included Yu Dawei 俞大维 (David Yule, 1897-1993), a US and German-trained specialist in mathematical logic then in charge of military technology in the Ministry of War. ${ }^{86}$ Reportedly, Yu asked Hua to tackle a critical war-related technical problem, the decoding of Japanese military telegraphy, and perhaps to the surprise of both, Hua solved it overnight. 87 As Hua told Weyl:

81 Weyl to Hua, October 7, 1943, Hua/SM/MVA II.

82 Hua to Weyl, November 1, 1943, Hua/SM/MVA II.

83 Chern to Gwen Black, December 1943, Hua/SM/MVA II.

84 Aydelotte to Commanding Office, and to Hua, January 7, 1944, Hua/SM/MVA II.

85 Hua to Weyl, January 2, 1944, Hua/SM/MVA II. Hua in this and several other letters presumably misspelled the word "attitude" as "altitude," which are automatically corrected in the quotes in this paper, as are other such obvious misspellings (for example, "stipence" for "stipend").

86 For more on $\mathrm{Yu}$, see Li 1992.

87 Wang 1999b, 118-121. On Hua solving Japanese codes, see Xu 2010, 4. 
My country put a good deal of war works before me. I solved some of them and passed some of them to specialists. I do not like to be a war-quitter. Thus I will come to Princeton after my work arrived at a better end which seems to be the summer. In the due time I hope the Institute would kindly reconsider the situation. 88

Hua then made what must have seemed to Weyl a somewhat surprising comment about which colleague at Princeton should speak on his behalf: "Dr. W. Y. Chang 张文 裕 (Zhang Wenyu, 1910-1992) knows me best, he is doing researches and learning modern techniques at Princeton. He, my honorable patriotic colleague, will be my representative and you may consult him all about me." 89 The fact that Hua did not mention Chern in this context probably gave Weyl and other IAS mathematicians some sense of their personal relationship.

An additional reason, unbeknownst to Weyl, for why Hua decided not to come to Princeton in early 1944 would be revealed many years later. It came to light when parts of his Chinese correspondence from this period were published in China in 1995. We now know that on January 15, 1944, about two weeks after he told Weyl that he could not come to the IAS due to both war work and family reasons, he wrote a letter to Chen Lifu 陈立夫, then the Chinese minister of education. In it, he acknowledged that he was grateful for a grant of $\$ 1,000$ from the ministry for his travel expenses to the US but explained that he would not undertake the trip during the winter break for four reasons. The first was that he expected it would take months for him to receive his passport and foreign exchange currency; the second was the difficulty of supporting his family in his absence; the third was his hope to continue to make contributions to national defense; and finally, he did not want to be overshadowed by Siegel at the IAS:

As to research, I and Siegel, former professor of mathematics at Göttingen University, have both developed independently an "automorphic theory of matrices," but my theory is actually broader and more precise than his, which has been praised and recognized by himself and Weyl. I have already three papers in press on this, totaling 150 pages (as you know mathematical papers are usually not very long, often 10 pages each). I have three more completed, totaling about 200 pages, with infinitely more ideas to come. Weyl has said that I have discovered a rich mine which can be exploited endlessly. At the present Siegel is at the Princeton Institute for Advanced Study. If I go there, I would benefit deeply from our discussions. Nevertheless, due to his age and seniority he enjoys a higher academic reputation than I. If I accept the IAS's invitation and go there, it may lead me to sacrifice the credit I am due for independent inventions and make me a

88 Hua to Weyl, January 2, 1944, Hua/SM/MVA II.

89 Hua to Weyl, January 2, 1944, Hua/SM/MVA II. Chang was a Chinese experimental physicist then visiting Princeton University. 
member of Siegel's school. Thus, I have to build a solid foundation before going abroad (of course it will be better if I can go abroad without accepting the IAS invitation). ${ }^{90}$

He went on to request funds from the ministry so he could hire some assistants to help him complete his book on the subject. He could then bring the book with him when he went abroad to make the world aware of China's wartime scientific achievements and improve its international image (Yuan 1995, 63). The letter worked; Hua soon received a sizable grant from the ministry (Yuan 1995, 64). ${ }^{91}$

Meanwhile, Weyl, unaware of Hua's full reasoning, replied on March 3, 1944, that he was sorry Hua could not come at this time but reassured him that the IAS stipend would be held for him for another year. Explaining to him that the IAS was a non-governmental institution with limited means and that "We realize of course that the $\$ 1,500$ which we offer you is inadequate when measured against your scientific work," Weyl nevertheless hoped that the Chinese side would eventually support his visit. He also promised to help Hua publish all his papers in the US. ${ }^{92}$

Weyl's sympathetic response drew out an emotional outpouring from Hua on his life's struggles and his hopes for Chinese mathematics. Writing on April 24, 1944, Hua first reported that he had been offered a high position in the Chinese National Resources Commission but that he was going to turn it down in favor of coming to Princeton, still hoping to arrive in the summer. He told Weyl that in the last three months he had worked fourteen hours every day so he could carry out both war-related work and his mathematical research, motivated by a strong sense of scientific nationalism:

Besides my intrinsic love on mathematics, there are several reasons which make me work hard. As you know, China is a backward country, in particular, backward in Science. To build up a new China is necessary to promote the Science in China to the world level. I will do my share and my best toward this aim. .3

90 Hua to Chen Lifu, January 15, 1944, printed in Yuan 1995, 62-63. The quoted Chinese text (Yuan 1995, 63): “就研究方面言, 罗庚与前哥廷根大学教授 Siegel 氏曾各独立发展 ‘数阵之自形函 数论', 而罗庚之理论实较其更为博广与精到 (已得其本人及 Weyl 二氏之谬许), 现已在刊布中者 有三文, 共百五十页左右 (数学文章不易写长, 常在十页左右, 此乃先生所素知也)。又有三文已有 成稿, 约二百页左右, 且余意无穷, 诚如 Weyl 教授所谓罗庚已获一重要结果之矿, 可以经久不竭 也。现 Siegel 氏在普林斯顿高研所。若罗庚前往, 当深获切碰碌磨之益。但其在学术界之资望, 为 年龄履历等关系而在罗庚之上, 若率尔前往 (接受高研所之邀请), 可能牺牲独立发明之令誉, 而变 为 Siegel 学派之可能, 是以不得不先定基础再行出国也 (如能不受高研所之邀而前往当更好)。” 91 See also an article by Heini Halberstam, a mathematician who knew Hua, in which he wrote that when the IAS invited Hua he declined "because C L Siegel was working there along somewhat similar lines" and he wanted to "develop his ideas independently" (Halberstam 2004). 92 Weyl to Hua, March 3, 1944, Hua/SM/MVA II.

93 Hua to Weyl, April 24, 1944, Hua/SM/MVA II. 
He recounted his lack of formal education and poor family background, which had driven him to work sixteen hours a day from a young age. This played a role in his determination to attain status: "One of my life-will is to get some honour from international recognition." He hastened to add, "I believe, some international recognition will also give the Chinese a confidence in Science. Such a confidence is very urgent for our present infant stage." He concluded this soul-searching discussion with an apology for his "poor English" and "non-sense talking." 94

Hua's correspondence with Weyl continued into the summer, mostly regarding the publication of Hua's several papers in the US, while little progress was made on his visit to the IAS. On June 29, 1944, Hua requested that Weyl give some reprints to Chern to send to him. ${ }^{95}$ On July 7, Hua simply reported to Weyl, "I asked for leave to my government, but so far received no definite instructions." 96 On September 6, Hua reported that he was "at the final stage for the preparation to come to Princeton," but the Chinese foreign minister had asked for evidence of his IAS status and stipend. Furthermore, he said that he would need to do some fieldwork near the war front, and that "It seems very probable that I am forced to arrive at Princeton after the war." 97 Weyl responded to Hua on September 26 (before seeing the latter's September 6 letter) to let him know that, like last year, if he did not arrive before January 29, 1945, the IAS would not be able to hold the stipend for him for the year and he would need to re-apply for the next year. He added that Chern was collecting materials to send him while offering critiques of one of Hua's papers. ${ }^{98}$ After receiving Hua's September 6 letter, Weyl promptly had Aydelotte send Hua the official letter he had requested, even though Weyl probably sensed that the chance of Hua coming that year was remote. ${ }^{99}$

As the prospect of Hua's visit to the IAS in 1945 grew dimmer, mathematics took center stage in Hua's communication with Weyl, and Weyl grew impatient with the quality of Hua's hastily drafted papers. In the September 26 letter, Weyl told Hua that he (Weyl) "had found a simpler proof for your decisive lemma on conjugate partitions" in one of the two papers Hua had sent him, and thus "I shall make no attempt to get this paper of yours published," although he promised to "try to take care of the other note." 100 In his next letter on October 2, 1944, Weyl offered serious criticisms of the second paper as well and conveyed the report on a third paper ("On Automorphic

94 Hua to Weyl, April 24, 1944, Hua/SM/MVA II. Weyl marked the "life-will" sentence in the margin.

95 Hua to Weyl, June 29, 1944, Hua/SM/MVA II.

96 Hua to Weyl, July 7, 1944, Hua/SM/MVA II.

97 Hua to Weyl, September 6, 1944, Hua/SM/MVA II.

98 Weyl to Hua, September 26, 1944, Hua/SM/MVA II.

99 Weyl to Hua, October 17, 1944, Aydelotte to Hua and to "Whom It May Concern," October 9, 1944, Hua/SM/MVA II.

100 Weyl to Hua, September 26, 1944, Hua/SM/MVA II. 
Functions V: General Theory") by a referee, who assessed it as "not ready to print," although it contained some new results. Weyl added a note of his own:

It seems to me that your general theory has not yet reached the stage where it is ripe for publication.... What you have does not go very much beyond a general program. Siegel has published nothing about the subject for the simple reason that he sees no way of overcoming the main obstacle, the parabolic corners. ${ }^{101}$

Weyl went on to chide Hua for preferring speed over quality and pleaded with him to be more meticulous in his mathematical work:

Dear Professor Hua, we here in Princeton really wish to help you. You have no doubt a lot of interesting material, but you must do your part and prepare your manuscripts much more carefully. Give some thought to the notations, which you are apt to choose too haphazardly, and check all the formulas! Could you not wait a few weeks before you send your manuscript out, and think yourself about how to improve the presentation? You can not expect that other people will busy themselves with revising and even rewriting your manuscripts. Your friends here are glad to correct your English, but you yourself must see to it that the mathematics is in good shape, free of mistakes, and arranged in a reasonable and readable way. ${ }^{102}$

The receipt of yet another paper in October 1944 from Hua provided Weyl with additional ammunition in his effort to convince Hua of the importance of care and the need to avoid haste: "Thinking your ideas over until they assume their simplest and most adequate form, complete formulation of the propositions, a well-planned notation, terminology and arrangement, correct references, etc., - all these things require much more care than you seem to be willing to bestow on them."103 Weyl was equally forthright and critical when Hua's first two papers discussed above came to him via the US State Department, which had set up a program in collaboration with the National Library of Beijing (Beiping), then in exile in Kunming, to publish works by Chinese scholars in the US. 104

Finally, a letter from Hua to Weyl, written on November 29, 1944, brought the news that "I received no complete answer yet" from the Chinese government as to whether he could be released for a visit to the US and "Thus I am obliged to give up the plan to

101 Weyl to Hua, October 2, 1944, Hua/SM/MVA II.

102 Weyl to Hua, October 2, 1944, Hua/SM/MVA II.

103 Weyl to Hua, October 2, 1944, Hua/SM/MVA II.

104 Harry R. Warfel to Weyl, November 4, 1944, and Weyl to Warfel, November 7, 1944, Hua/SM/MVA II. Warfel was then chief of Book and Publication Section, Division of Cultural Cooperation of the US State Department. Hua had explained to Weyl earlier that he was submitting his papers through that program so he could receive some honoraria. Hua to Weyl, July 7, 1944. 
come to Princeton." While expressing his regrets and apologies profusely, he added, "Nevertheless, I am not completely disappointed. To stay with my country and my family at the most critical time gives me a great mental comfort, which is rather important in the oriental psychology."105

However, nine days earlier, on November 20, 1944, Hua had written a letter to A. Adrian Albert at the University of Chicago with a different message:

I did some war work. The government may permit me to have a refreshment for visiting the Allies. I wish to come to U.S.A. But there is still no appropriate chance. The Institute for Advanced Study offered a $\$ 1500$-stipend for me. But it is very insufficient for me and my family. State Department invites several Chinese Profs. to visit the U.S.A. I rather like and admire their opportunity, and hope to follow suit. But I don't know "how". Please, just for trial, if you don't mind, to write a letter for recommendation to the State Dept. Certainly, a chance, if any, from your university, my respectful place, will honour me greatly. 106

Praising Hua as "an excellent mathematician," Albert shared Hua's letter to him with Weyl as well as a letter from the State Department indicating that it might be able to pay for Hua's expenses if the IAS renewed its stipend for Hua for the next year. Albert added that he hoped that the IAS "succeeds in bringing him to this country." 107

Such a turn of events appeared to Weyl to be double-crossing on Hua's part and wore his patience to the breaking point. He poured his frustration with Hua into a response to Albert:

Loo-Keng Hua is evidently a very gifted mathematician, probably the most gifted Chinese besides Chern. He has plenty of ideas. But he is also most uncritical. At least 80 per cent. of the vast material which he has sent me during the last two years in an almost continuous stream, was quite superficial. His "life-will to get some honor from international recognition" (of which he once wrote me) hastens him on and endangers the soundness of his work.108

Weyl recounted how the IAS had invited Hua along with Chern in 1943 so he could work with Siegel:

Chern arrived in the summer of 1943. But Hua treated the invitation in a somewhat dilatory manner, and remained curiously vague about any steps taken by him. Three

105 Hua to Weyl, November 29, 1944, Hua/SM/MVA II.

106 Excerpt from Hua to A. A. Albert, November 20, 1944, Hua/SM/MVA II.

107 A. Adrian Albert to Weyl, February 6, 1945, and Willys R. Peck to Albert, January 30, 1945, Hua/SM/MVA II. Peck was acting assistant chief, Far Eastern Branch, Division of Cultural Cooperation, US State Department.

108 Weyl to Albert, February 17, 1945, Hua/SM/MVA II. 
times we agreed to defer the invitation. In the meanwhile the most glorified stories about it found their way from the Chinese into the American press. 109

The latest messages Hua sent to Albert and Weyl clearly intensified Weyl's mounting skepticism toward Hua, as he told Albert the following about the afore-mentioned letter Hua had written to him (Weyl) on November 29, 1944, concerning his inability to come:

$[\mathrm{H}] \mathrm{e}$ consoled himself with the thought, "To stay with my country and my family at the most critical time gives me a great mental comfort, which is rather important in the oriental psychology." See the date of your letter. . . . The whole correspondence has indeed been a lesson to me in "oriental psychology". Poor fellow! How he bungles his own affairs. ${ }^{110}$

Yet just as Weyl could not hide his frustration with Hua's apparently incoherent behavior, he could not refuse to help him either:

Anyhow after these antecedents I feel naturally hesitant to recommend renewal of our invitation right now. Nor would that seem to meet Dr. Hua's wishes. However, in view of the encouraging reply of the State Department, of which I am keeping a copy, I shall discuss the matter with Dr. Aydelotte when he returns to Princeton within the next two weeks. 111

He did end the letter to Albert by asking plaintively, "Could you not persuade your university to invite Hua?" 112

Perhaps the venting with Albert helped Weyl to regain his perspective on Hua as an imperfect talent. In his letter to Hua on February 23, 1945, he expressed his regret about Hua not coming but also his sympathy: "I understand very well the difficult situation in which you find yourself." He did tease him a bit by reporting that:

Siegel gave us an awfully interesting course on automorphic functions of several variables during the first term. I am sure you would have enjoyed it! Did Chern report to you about it?113

109 Weyl to Albert, February 17, 1945, Hua/SM/MVA II. Weyl was referring to the sensational reports in the Chinese press, which stirred media and official interest in the US, that Hua had been invited by Albert Einstein to come to the IAS to give lectures. See R. Edgar (of the US Office of War Information) to Aydelotte, telegram, March 31, 1944; Aydelotte to Edgar, April 1, 1944; Aydelotte to Watson Davis (director of Science Service), April 26, 1944; all in Hua/DO/Mem.

110 Weyl to Albert, February 17, 1945, Hua/SM/MVA II.

111 Weyl to Albert, February 17, 1945, Hua/SM/MVA II.

112 Weyl to Albert, February 17, 1945, Hua/SM/MVA II.

113 Weyl to Hua, February 23, 1945, Hua/SM/MVA II. 
Hua's reply, dated March 29, 1945, must have alerted Weyl to the strain in the Hua-Chern relationship, if he had not sensed it before. Besides reporting that his living and working conditions had worsened, Hua expressed frustration with his continued lack of international scientific communication (and with Chern): "It is a great pity that Chern did not tell me a single word about Siegel's interesting course." He pleaded with Weyl to send Siegel's lecture notes to him, perhaps via Yu Dawei, who was visiting the US at the time. ${ }^{114}$

Nothing happened for a while, not even after the end of the war in summer 1945. But then, on February 2, 1946, the day of the Chinese Lunar New Year, Hua wrote to Weyl to submit a paper and report some positive developments for his visit to the IAS:

I was told that Dr. Chern will come back pretty soon. It is a good news to me. I can well image that this year shall realize my dream to be a pupil in the Princeton school. This plan was delayed for a long time by the war-work and the shortage of members of our department. To the first problem, I now have received an understanding from our Minister of War. To the second problem, Dr. Chern's kind return would be a resolution of it. 115

Two weeks later he reported to Weyl again that he was leaving for a short visit to the Soviet Union at the invitation of the Soviet Academy of Sciences, but planned to visit the US afterwards: "If everything is in order, it is very possible, I shall come to U.S.A. in June or July." There was no mention of a stipend this time; he was coming to visit the US with funds from the Chinese government on a discrete mission with several other Chinese scientists and science students, including the future Nobel physics laureate Tsung-Dao Lee 李政道 (Li Zhengdao, 1926-), to learn to make atomic bombs. Frustrated by US security restrictions, members of the mission would later find their way into American universities as visiting scientists or graduate students (Wang, Li and Dai 2006).

Finally, on the eve of his departure for the US, Hua wrote excitedly to Weyl on September 1, 1946, more than three years after they had started the process of bringing him over to the IAS:

It is beyond of my ability to describe my happiness as my long time dream can be fully realized. Now I finished all necessary process to come to U.S.A., my ship will set forth on September 2. If everything according to plan, I shall arrive at Princeton before the end of Sept. and at that time I shall meet you, the world's greatest mathematician, honorable teacher of our age. ${ }^{116}$

114 Hua to Weyl, March 29, 1945, Hua/SM/MVA II.

115 Hua to Weyl, February 2, 1946, Hua/SM/MVA II.

116 Hua to Weyl, September 1, 1946, Hua/SM/MVA II. 
He ended by expressing his regret over the report that Siegel was returning to Göttingen: "I hope I am not too late to be a student of him."117 Weyl circulated Hua's announcement with other members of the IAS School of Mathematics, including Albert Einstein, Siegel, and Veblen. ${ }^{118}$

At long last, Hua arrived by ship at San Francisco in late September 1946 and filled out his registration form at the IAS on September 24, recording his visa as being that of a "government official" expiring on August 5, 1947. Under the question of degrees, Hua wrote simply, "No degrees - not a university man."119

As a testimony to the importance of person-to-person interactions and the true talent of Hua, once he made direct contact with Weyl and other members of the Princeton community of mathematicians, including those at nearby Princeton University, they quickly came to appreciate his intellectual power and enjoyed his company. Weyl wrote to Aydelotte on January 17, 1947, to request funding for Hua as a supplement to his Chinese grant:

It would be a very good thing if we also could help Hua a little bit financially. He has turned out to be a very valuable member of our group and if Siegel returns in time, Siegel, Hua, and [Leslie G.] Peck would make an excellent team. ${ }^{120}$

By March 1947, Weyl, having worked with both Chern and Hua, was able to offer a fascinating comparison between the two in a letter to the mathematician S. S. Cairns of Syracuse University:

Now it is clear that it is difficult for anybody to stand against such a truly noble man of great charm and talents as Chern, and indeed I would say that Hua is the less harmonious personality of the two. Nor has he gone through the classical Chinese education with its great formative power, as Chern did. Also, in his mathematical work Hua is of a more eruptive type than Chern. He works at enormous speed and is a prolific writer. While not everything is first rate, his papers are certainly full of original, even brilliant ideas. In that respect, in the wealth of ideas, he even may exceed Chern. It makes him a very stimulating man to have around. He is cooperative and communicative and has a pleasant personality. We are all fond of him here and consider him a very valuable member of our group. ${ }^{121}$

117 Hua to Weyl, September 1, 1946, Hua/SM/MVA II.

118 Notation on Hua to Weyl, September 1, 1946, Hua/SM/MVA II. It is not clear whether Siegel's departure from and Hua's coming to the IAS in 1946 were purely coincidental, given Hua's earlier concern about being overshadowed by Siegel.

119 Hua's registration form, September 24, 1946, Hua/DO/Mem.

120 Weyl to Aydelotte, January 17, 1947, Hua/SM/MVA II.

121 Weyl to Cairns, March 12, 1947, Hua/SM/MVA II. 
Hua made such a positive impression on key people like Weyl that Aydelotte was led not only to award him $\$ 500$ for his work in 1946-1947, but to offer him an additional $\$ 2,500$ to extend his stay at the IAS in 1947-1948. Aydelotte announced this to Hua in a letter dated March 4, 1947, congratulating him "on the high quality of the scientific work which you are doing at the Institute and the great satisfaction which it gives us all to have you here." 122 In mid-April, the IAS increased Hua's 1947-1948 stipend to $\$ 3,000$ so he could bring part of his family to the US. ${ }^{123}$ After Princeton University appointed Hua as a lecturer with a salary of $\$ 2,000$ for 1947-1948, the IAS made an exception to its rule against outside teaching, although it reduced his stipend to $\$ 2,000.124$ It also assisted him in receiving a successful operation at Johns Hopkins Hospital in Baltimore in the spring of

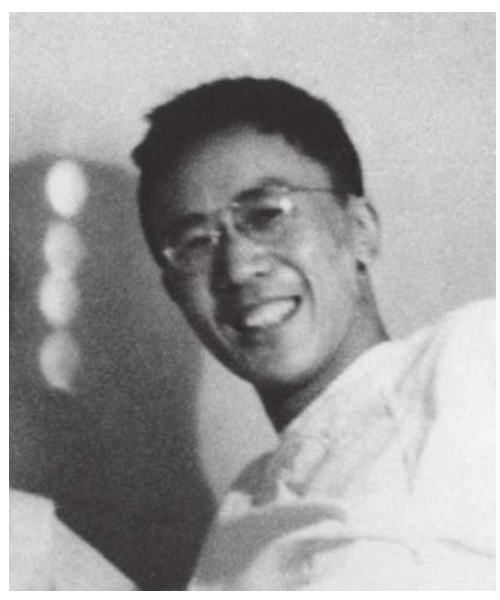

Figure 5: Hua Luogeng in spring 1947 at Johns Hopkins Hospital, Baltimore, after a successful operation to reduce deformities on his left leg (Wang 1999b). 1947, which greatly reduced the deformity on his left leg (Figure 5). ${ }^{125}$

Hua took full advantage of the supportive and stimulating environment at Princeton and carried out a rigorous program of mathematical research and teaching as well as numerous invited talks at major universities in the US. By early 1948, he sought to find a teaching position in an American university that would allow him to stay for another one to three academic years. The reason, as Veblen explained to H. R. Brahana, acting head of the Mathematics Department at the University of Illinois, was both political and professional:

It is undesirable for Hua to return to China at the present time, largely because he did scientific work for the Chinese government during the war. At that time he enjoyed the rank and emoluments of a general. But as things are now, if he went back it would be dangerous for him to refuse to do this kind of work, and on the other hand if he engaged

122 Aydelotte to Hua, March 4, 1947, Hua/SM/MVA II.

123 Aydelotte to Hua, April 14, 1947, and Aydelotte to Veblen, April 12, 1947, Hua/SM/MVA II. The IAS assisted with the paperwork on visas for Hua's family. See Aydelotte to American Consul, Shanghai, May 28, 1947; Francis H. Styles (American consul in Shanghai) to Aydelotte, June 21, 1947; Aydelotte to Ministry of Foreign Affairs, China, and to Whom It May Concern, July 5, 1947; Aydelotte to Styles, July 15, 1947, all in Hua/SM/MVA II.

124 S. Lefschetz to Aydelotte, June 2, 1947; Aydelotte to Veblen and M. Morse, June 4, 1947; Aydelotte to Morse, June 5, 1947; Aydelotte to Hua, June 5, 1947, all in Hua/SM/MVA II. Lefschetz was chair of mathematics at Princeton and had hoped that the IAS would have allowed Hua to keep the full $\$ 3,000$ stipend.

125 See Aydelotte to Francis H. Styles (American consul general in Shanghai), July 15, 1947, in Hua/DO/Mem. See also Wang 1999a, 140-141. 
in it, it would be disastrous for his scientific work. Therefore it would be better for him to stay for at least a couple of years longer in the United States. ... I think that this affords an unusual opportunity to secure the services of a really first-rate mathematician, for Hua can be classified as first-rate among the mathematicians of the world. ${ }^{126}$

Veblen's letter was part of a campaign that he and Weyl carried out on Hua's behalf in mid-February 1948. Hua had already applied for a visiting professorship at Syracuse and received a positive recommendation by the Mathematics Department, but it was held up by the university administration. ${ }^{127}$ Uncertain about Syracuse, Weyl, with Veblen's support, wrote a letter dated February 12, 1948, to other leading mathematics departments, including Illinois', advertising Hua's "availability" for one to three years. Calling him "a very pleasant man," Weyl's letter provided a very positive assessment of Hua and his mathematical work:

He is a man simply brimming with ideas. He has done a number of excellent things in analytic number theory; most of this work is along Vinogradoff's lines. Right after the war he was invited to Moscow. During the closing years of the war he duplicated some of Siegel's research on automorphic functions of several variables (symplectic geometry). He has published about 70 papers on a great variety of subjects....

Weyl did not hide his earlier criticism of Hua but praised him for his improvement and the high quality of his research at the IAS:

In his younger years he suffered from a lack of good judgment in discriminating between important and trivial results; a trait so often found in people of gushing productivity. Since I can watch him he has improved considerably in this respect; and anyhow among his papers there is a high percentage of first-rate contributions to mathematics. During his stay at the Institute Hua has worked on what he calls geometry of matrices, on automorphisms of the symplectic group, and has collaborated with Dr. [Irving] Reiner (from Cornell) on generators of the modular and other groups. He also collaborated with [Harry] Vandiver on problems in the direction of Waring's problem. Moreover he has improved a number of Vinogradoff's results. You see from this that Hua is ready to cooperate with other people. Indeed, he has been one of the most stimulating elements in our group here at the Institute and Princeton University. ${ }^{128}$

126 Veblen to H. R. Brahana, February 12, 1948, in Hua/SM/MVA II. In his letter, Veblen called Hua "a man of attractive personality, and is unquestionably one of the two best Chinese mathematicians, the other one being Shiing-Shen Chern. ..."

127 The university administration objected that Hua would not attract students as a one-year visiting professor and would thus constitute "an expensive luxury" with a $\$ 7,000$ salary. See Weyl to Stewart S. Cairns, January 23, 1948; esp. Cairns to Weyl, January 27, 1948; Weyl to Cairns, February 6, 1948; Veblen to Cairns, February 23, 1948, all in Hua/SM/MVA II. Cairns was chair of the Department of Mathematics at Syracuse.

128 Weyl to a list of mathematicians, February 12, 1948, Hua/SM/MVA II. 
Weyl and Veblen's campaign on Hua's behalf quickly resulted in several responses of interest and a definite job offer. On February 17, 1948, Brahana of Illinois wrote a letter to Veblen with an offer to Hua as a "Visiting Professor" with a salary of $\$ 6,000$ for 1948-1949. He told Veblen, "my intention would be to recommend renewal for one or two years thereafter."129 Veblen talked the offer over with Hua, who quickly accepted it. ${ }^{130}$ As a measure of the quality of his research and mentorship, Irving Reiner, who collaborated with Hua at the IAS as a postdoc and who had been invited to stay at the IAS for another year, was willing to move with Hua to Illinois as an instructor. ${ }^{131}$

Hua's need to change his visa from that of a government official to the category of "non-quota," allowing him to teach at Illinois, necessitated a trip to Montreal, Canada, in May 1948. It was in the context of certifying his active membership at the IAS that Weyl, himself an immigrant, offered an eloquent testimony of Hua's talents, contributions to American science, and implicitly the value of immigrants and international scientific exchanges:

Scientific knowledge grows by the thinking of the individual solitary scientist and by the communication of ideas from man to man. Dr. Hua has contributed to the store of mathematical ideas by the advanced research work in higher mathematics which he has pursued at the Institute. Teaching and learning, the communication of ideas, is performed at the level of our Institute not only by courses of lectures and seminars, but also by individual lectures on selected topics, and by continuous discussion of problems. As a mature Professor of Mathematics of wide experience, Hua has been of great value in this respect to our whole group, especially to the younger members, by the stimulus he has provided. There is no doubt that many American students of mathematics have

129 Brahana to Veblen, February 17, 1948, Hua/SM/MVA II. Brahana had received both Weyl's group letter and a personal appeal from Veblen. Veblen to Brahana, February 12, 1948, Hua/SM/MVA II.

130 Veblen to Brahana, February 20, 1948, Hua/SM/MVA II. Meanwhile, Harvard could only offer Hua an instructorship with $\$ 3,500$, which was not enough for his needs. D. V. Widder to Weyl, February 20, 1948, and Weyl to Widder, February 24, 1948, Hua/SM/MVA II. The University of Wisconsin, Madison, also expressed interest in Hua as a one-year visiting professor. R. E. Langer to Weyl, February 20, 1948, and Weyl to Langer, February 24, 1948, Hua/SM/MVA II. Weyl revealed to Langer that at least one other university was interested in Hua and ended the letter by proclaiming, "He really is a very good man!" Marshall $\mathrm{H}$. Stone, chairman of the Mathematics Department at Chicago, told Weyl that Hua "has many friends and admirers here in Chicago. ... However, I do not foresee any immediate possibility of inviting him." Stone to Weyl, February 20, 1948, Hua/SM/MVA II. Stanford's Mathematics Department said that it had made an offer - not clear what kind - to Hua in April 1947 but it "did not materialize mainly because of his health condition." G. Szegö to Weyl, February 18, 1948, Hua/SM/MVA II.

131 Veblen to Brahana, February 23, 1948, Hua/SM/MVA II. 
greatly benefited from contact with him and from the inspiration he has given them during his stay at the Institute. ${ }^{132}$

Once Hua moved to Urbana, Illinois, he was able to bring his wife, Wu Xiaoyuan 吴 篵元 and three young sons from China, leaving behind an infant daughter, Hua Su 华 苏, and a nineteen-year-old daughter, Hua Shun 华顺, who chose to stay and join the underground Chinese Communist Party over an offer to attend an American university that her father had arranged for her (Wang 1999a, 145-146).

\section{Making choices, 1948-1950}

Just as Hua's visiting appointment at Illinois postponed a choice between China and the US for the time being, and as the Huas finally enjoyed a measure of peace, quiet, and partial family reunion, the Cherns felt the need to make a decision of their own. As mentioned above, the standard accounts, including Chern's own, of his second move to the US highlighted the role of the famous telegram from Oppenheimer to Chern in 1948 that offered assistance to him to come to the US (Chern 2002d, 13; Xu 2002).

But such accounts only told part of what happened. Correspondence in the IAS archives has revealed that it was Chern who had first recognized his precarious situation and sought assistance to get out of China and come to the US. On November 9, 1948, Chern, then serving as acting director of the Institute of Mathematics of Academia Sinica in Nanjing, had written a letter to Solomon Lefschetz, chair of the Mathematics Department at Princeton University, in which he first described the personal and professional difficulties he encountered in China due to the civil war:

You perhaps have followed the recent developments in China. The general situation is very unstable and the present hardship is much worse than the war years. No matter what the outcome is, I believe that it will be quite a few years before mathematical research in China can have any hope of real progress. You know I have always hoped for the best for my country and have so far not waivered about hardship. However, the conditions are now such that I may not be able to continue any work. Daily necessities such as rice, fuel, etc, are now taking a great deal of my energy.

He then announced his intention to move with his family to the US and asked for assistance:

Under such circumstances I think that you must be sympathetic to my intention to pull out of this place, although I made this decision not without pain. I am therefore asking you whether you know there is at present any possibility for me to get a position in the

132 Weyl to Whom It May Concern, May 18, 1948, Hua/SM/MVA II. Note on the letter indicated that it was delivered to Hua himself to show to the American consul in Montreal. 
US, either on a temporary or permanent basis. I shall be ready to leave at any time. However, as I shall naturally bring my family (wife and two kids) along, it will probably take some time in the preparation. Looking forward for your help and advice. . . ${ }^{133}$

What this letter implies is that Chern was not ignorant of the civil war, as he would later recall, but seemed to be very much aware of what was going on around him politically. After soul-searching and balancing between his professional and personal desire to continue scientific research and his sense of patriotic duty to help develop Chinese science, he decided that for the moment it was best to leave China and continue his professional pursuit abroad in the US.

What is not definite but plausible, judging from the surviving IAS archives, is that this letter led directly to Oppenheimer's telegram to Chern on November 19, 1948. Unfortunately, we do not have the receipt date of Chern's Nov. 9 letter at Princeton, but we do know how long airmail usually took at the time between China and the US. A letter Chern sent to Oppenheimer soon after was dated December 21, 1948, and a note on it said that it was received on December 29, 1948. ${ }^{134}$ At this rate it was entirely possible that the chain of actions at the IAS was triggered by Chern's letter to Lefschetz. Yet already on November 11, 1948, only two days after Chern wrote his letter, Gwen Blake, secretary of the School of Mathematics, sent a memo to E. W. Leary, assistant to Oppenheimer, with basic information about Chern at the suggestion of Veblen. ${ }^{135}$ So it was also possible that besides and before the arrival of Chern's November 9 letter, Chern had written to Veblen with a similar request or that the IAS, under Veblen's initiative, did indeed take the lead in offering Chern the assistance to come to the US without Chern having asked for it. ${ }^{136}$ In his letter response to Oppenheimer on November 22, 1948, Chern also mentioned, "my friends in the US are making arrangements for me to make a trip to the US in the academic year 1949-50."137 Indeed, Veblen and Weyl were among these friends, as Weil's later recollections confirm. For his part, Weil remembered that during this period he was watching what was going in China "with increasing anxiety for his [Chern's] fate" and that Marshall Stone of the

133 Chern to Lefschetz, November 9, 1948, Chern/SM/MVA I.

134 Chern to Oppenheimer, December 21, 1948, Chern/DO/Mem.

135 Blake to Leary, November 11, 1948, Chern/SM/MVA I.

136 The IAS archives does have copies of both Chern's November 9 letter to Lefschetz and the latter's group letter to American mathematicians seeking a position for Chern, dated November 24, 1948, and stating that "I have just received word from Professor S. S. Chern. . . ." It also has a note from E. W. Leary to Veblen, dated November 18, 1948, reporting on what the Visa Division in the US State Department told her about how to help Chern get a US visa: "we send a certified cable (including terms of our contract)" to both Chern and the American consul in Nanjing (All in Chern/SM/MVA I).

137 Chern to Oppenheimer, November 22, 1948, Chern/DO/Mem. 
University of Chicago, where Weil had moved in 1947, had offered Chern a visiting appointment (Weil 1996, 74).

In any case, Oppenheimer sent Chern his telegram of November 19, 1948, which consisted of one sentence: "If there should be any steps that you would like to have us take in the next months to facilitate your coming to this country please let us know" (Figure 2). And it had the approval of such luminary members of the School of Mathematics as Einstein, Marston Morse, John von Neumann, Siegel, Veblen, and Weyl. ${ }^{138}$ Thereafter, things moved quickly. Chern received the cable on November 21 in Nanjing and started making inquiries and preparations. The next day he wrote a remarkable letter to Weyl giving his assessment of the Chinese situation and explaining his choices. It went beyond the personal and professional issues he had focused on in his letter to Lefschetz, delving into the socio-political situation in China (Figure 6).

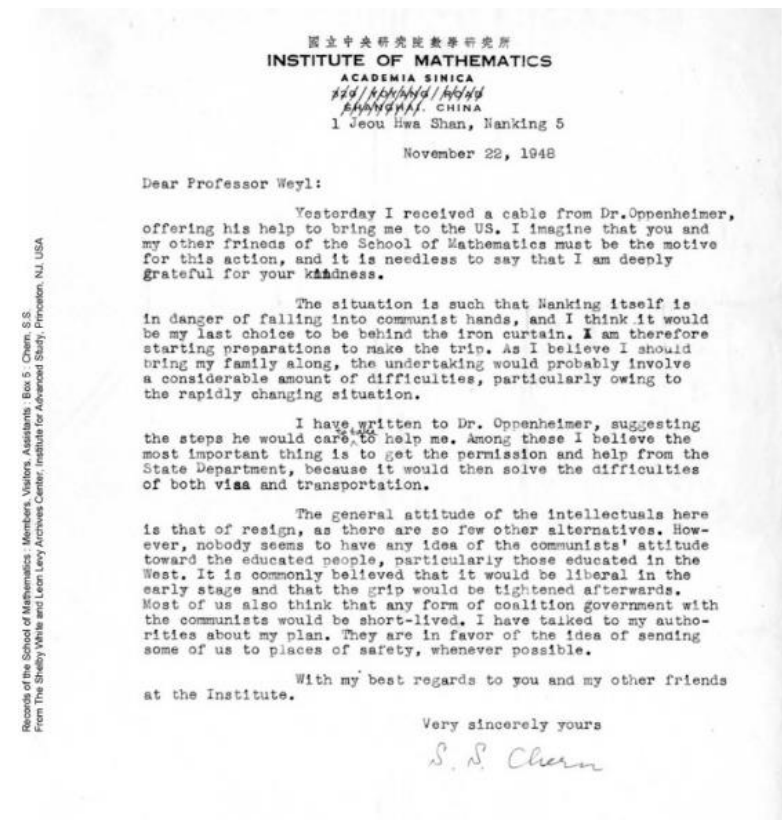

Figure 6: Shiing-shen Chern to Hermann Weyl, November 22, 1948, on the political situation in China at the time of his departure for the US.139

He started by thanking Weyl and colleagues for their possible part in what led to Oppenheimer's telegram:

Yesterday I received a cable from Dr. Oppenheimer, offering his help to bring me to the US. I imagine that you and my other friends of the School of Mathematics must be the

138 Oppenheimer cable to Chern, November 19, 1948, Chern/SM/MVA I.

139 Chern/SM/MVA I. 
motive for this action, and it is needless to say that I am deeply grateful for your kindness.

He then situated his own choices in the context of Chinese and international politics:

The situation is such that Nanking [Nanjing] itself is in danger of falling into communist hands, and I think it would be my last choice to be behind the iron curtain. I am therefore starting preparations to make the trip. As I believe I should bring my family along, the undertaking would probably involve a considerable amount of difficulties, particularly owing to the rapidly changing situation.

He concluded the letter with rather astute observations about the Chinese scientific community at the time:

The general attitude of the intellectuals here is that of resign, as there are so few other alternatives. However, nobody seems to have any idea of the communists' attitude toward the educated people, particularly those educated in the West. . . . Most of us also think that any form of coalition government with the communists would be short-lived. I have talked to my authorities about my plan. They are in favor of the idea of sending some of us to places of safety, whenever possible.

Here, what Chern confided in Weyl was that he was making the choice of going to the US based not only on professional but also political grounds - the need to escape what he feared would be an unfriendly new political system. Notably, he was uncertain about the position of and conditions for western-educated scientists and other intellectuals in the future. He clearly was not ignorant of the political situation, as he later remembered; he actually thought deeply about it.

What followed was a flurry of cables and some letters between Chern, Oppenheimer, and the US and Chinese governments that helped arrange for the Cherns' departure for the US: Chern was given a three-year appointment at the IAS (privately "binding on neither party") with an annual salary of $\$ 4,000 .{ }^{140}$ Finally, with passports, visas, and airplane tickets in hand for himself, his wife, Shih-Ning Cheng 郑 士宁 (Zheng Shining), a biologist by training, and his son and daughter, Paul and May, Chern wrote one last letter, dated December 22, 1948, from China to Oppenheimer with good news: "I am scheduled to leave Shanghai by air on December 29th" (it was later postponed to December 31). He expected to spend two weeks on the West Coast before

140 Chern cables to Oppenheimer, November 27, 29, 1948; Oppenheimer cable to Chern November 29, 1948; Mrs. John D. Leary to P. Yen (Chinese consulate in New York), November 30, 1948; Oppenheimer cable to American Embassy in Nanjing, December 1, 1948; Chern to Oppenheimer, December 2, 1948; Chern cable to Oppenheimer, December 10, 1948; Oppenheimer to Whom It May Concern, December 10, 1948; Chern to Oppenheimer, December 14, 1948, all in Chern/DO/Mem. The quote was from Chern's letter to Oppenheimer on November 22, 1948. 
heading to Princeton via Pasadena and Chicago by late January 1949, and asked that his mail be forwarded to his friend, the Chinese American linguist Yuen Ren Chao 赵元任 (Zhao Yuanren, 1892-1982) at the University of California, Berkeley. ${ }^{141}$

The Cherns landed in San Francisco, as mentioned at the beginning of the paper, on the evening of New Year's Day 1949. Weil, who would help Chern to gain not just a visiting position but a full professorship with tenure at Chicago, welcomed the Cherns on their way to Princeton and described the scene years later:

On that day I met his wife and children for the first time, and remember the occasion vividly. Chern, in his fur cap, looked very much the Manchurian general. But to me the most unforgettable sight was his daughter May, a small girl not yet two years old, all wrapped up in white furs; nothing more lovely could have been imagined. (Weil 1996, 74)

Chern would work at the IAS during spring 1949 and make the obligatory trip to Canada in May so he could return to the US with a new "non-quota" immigrant visa to accept the position at Chicago. Even though the notoriously racist "Chinese Exclusion Acts" were abolished in 1943, the discriminatory quota system still made it extremely difficult for Chinese immigrants to become permanent residents. Like Hua before him, Chern accomplished the latter with strong support from Veblen and Weyl, who vouched for him as "an exceptionally meritorious" immigrant. ${ }^{142}$

As the Cherns settled in Chicago, it was the Huas' turn now to make hard choices in nearby Urbana. Chern and Hua actually met, as mentioned above, and talked about their respective decisions: Chern's to stay, which was not surprising given his prognosis of Chinese politics, as revealed in his letter to Weyl on November 22, 1948, and Hua's to return. For Hua, there is no doubt that all the social-political factors, especially his Chinese nationalism, disgust with the Nationalists, growing sympathy and support for the Chinese Communist Party, and resentment of American racism, as articulated well by Salaff and Wang Yuan, played a major part in his decision to return home. Wang Shifeng 王时风 (1913-1992) and Qian Wen 钱闻 (1915-2001), two of Hua's longtime close friends in China, were communists, and Wang Shifeng continued to correspond with Hua when the latter was in the US (Qian 2017). Hua's trip to the Soviet Union in 1946 had left him with a favorable impression of Communist science policy. Shortly after his return from the Soviet Union and before his departure for the

141 Chern to Oppenheimer, December 22, 1948, Chern/DO/Mem. In his later autobiographical note, he said it was December 31, 1948, when he and his family flew from Shanghai to the US on a Pan-Am plane (Chern [1988] 1989, 13).

142 Veblen to Commissioner of Immigration and Naturalization Service, April 13, 1949; Veblen to Henry L. Mulle (of the INS), April 8, 1949; Weyl to G. de B. Robinson and to Richard Brauer, May 16, 1949, all in Chern/SM/MVA I. The quote is from Veblen to Mulle. 
US in 1946, Wen Yiduo 闻一多 (1899-1946), the well-known leftist writer and one of Hua's closest colleagues at Tsinghua in Kunming, was assassinated by government agents. It intensified his growing disgust with the Nationalists (Wang 1999a, 126-131). As early as September 9, 1949, Hua had written to Xu Lizhi 徐利治 (1920-2019), a Chinese mathematician who had served as his teaching assistant and who had joined the Chinese Communist Party in 1946, that he would return to China "in the not-too-distant future" (回去是不太远了) (Hua [1949] 2009, 243).

Yet it is possible that other factors of a personal or professional nature also played a part, at least a minor one, in Hua's decision to return. In his biography of Hua, Wang Yuan wrote about the suggestion that Hua's daughter Hua Shun influenced his decision to return: "although this might be so, it could not have been the deciding issue" because he always "made his own decisions" (Wang 1999a, 148). But it is at least conceivable that her political orientation-and decision to stay in China instead of coming to the US - did figure in his thinking, even if we discount her direct influence on him. Likewise, the fact that his infant daughter, Hua Su, had been left behind in China must have been a factor in his deliberations. ${ }^{143}$ According to Xu Lizhi, Hua was also concerned that his three sons would be drafted to serve in the US military if they were to stay and reach adulthood (Xu, Yuan, and Guo 2009, 227). ${ }^{144}$

Finally, it is also at least conceivable that the fact that Hua only had a visiting professorship at Illinois - not a regular full professorship, as it was widely reported when he returned to China - played a part, again perhaps a small one, in his decision to return (Wang 1999a, 145). ${ }^{145}$ Considering that Hua's 1943 decision not to come to the IAS was in part due to the slight he felt when he saw that the IAS had offered him less money than Chern, it is perhaps not unreasonable to conjecture that the fact that Chern now had a permanent full professorship at the more prestigious University of Chicago, in contrast to his visiting professorship at Illinois, helped at least to sway him toward a

$143 \mathrm{Xu}$ Yichao 许以超, a longtime member of the Institute of Mathematics of the Chinese Academy of Sciences and a graduate student of Hua's in the 1950s, believed that Hua's return was due in part to Hua Shun's influence: "He returned to China in 1950, when his eldest daughter persuaded him. His eldest daughter Hua Shun was an underground Chinese Communist" (他是 1950 年回来的, 当时是他大女儿给他做的工作, 他的大女儿华顺是地下党) (Xu Yichao interview by Guo Jinhai and Zeng Hui 曾汇, May 19, 2019, Beijing).

$144 \mathrm{Xu}$ remembered hearing Hua making statements to such effect during the Thought Remolding campaign in the early 1950s in Beijing.

145 Wang 1999a stated that Hua was appointed a "full professor" at Illinois, but according to Brahana's afore-mentioned letter to Veblen on February 17, 1948, making the offer to Hua, as well as the University of Illinois' official records, Hua's appointment was that of a "visiting professor." See, for example, the University of Illinois Board of Trustees minutes on July 28, 1949, which listed Hua as a "Visiting Professor" with an annual salary of $\$ 7,500$ (Board of Trustees 1950). Linda Stahnke Stepp of the University of Illinois Archives, in an email to Zuoyue Wang on September 18, 2017, confirmed that Hua "was a visiting professor for his time with the University of Illinois at Urbana-Champaign." 
return to China. It is of course likely that all these factors combined to make it attractive and even compelling for Hua to return to China in 1950.

Although these turns of events in 1950 separated Hua and Chern, their connections with each other and association with the IAS did not end there, even as they went on to pursue very different lives and paths in mathematics in China and the US. After his return to China, Hua suffered numerous political attacks during various political movements, especially during the 1957 Anti-Rightist Campaign and the 1966-1976 "Cultural Revolution," for his "individualism" and past association with the Nationalist government. But he was also able to play a leading role, from his longtime position as the founding director of the Institute of Mathematics of the Chinese Academy of Sciences, in training young mathematicians and in developing Chinese mathematics, especially in computing and applied mathematics (Wang 1999a; Xu 2015, 15-91; Richard 2010; Hudeček 2017). In setting up his new institute in the early 1950s, he drew inspiration from the Soviet practice of developing all fields of mathematics in order to serve national needs while criticizing the way Chern had organized his teaching activities in 1946 - aiming to achieve international excellence in topology alone. Hua claimed that Chern's approach was the result of following the advice of "an 'authoritative' American scholar" at the IAS and was detrimental to Chinese mathematical development (Hua 1953, 3). ${ }^{146}$ In one of his first communications with the IAS after his return to China, dated April 15, 1951, Hua asked Weyl to return the $\$ 10,000$ grant Weyl had received from the Academia Sinica to his new institute in Beijing. ${ }^{147}$ Weyl and the IAS refused, citing US laws against such transactions with China at the time and the competing claim from the Academia Sinica in Taipei. Indeed, the IAS decided to return the funds to the latter via the US State Department in 1953. ${ }^{148}$ Then, in 1980, just as he set out to revisit the US, including the IAS, for the first time since 1950, Hua again wrote to the IAS about these funds both directly and indirectly, through a Bank of China agent in the US. The IAS responded (politely to Hua but angrily to the agent, who had asked not only for the funds but also for interest) that it

146 Hua did not mention Chern explicitly or name the IAS scholar, but it is likely he was referring to Weyl, given Chern's above-mentioned correspondence with Weyl and invitation to him to visit China in 1946.

147 Hua's original letter appears to have been lost, but it is mentioned in Weyl's response to him on May 8, 1951, in DO/Fac/Weyl-Acad Sinica.

148 See correspondence in 1950-1953 in DO/Fac/Weyl-Acad Sinica. Zhu Jiahua 朱家骅 (Chu Chia-hua), president of the Academia Sinica, then in Taiwan, had written to Weyl on August 31, 1950, for a return of the funds via Yuen Ren Chao, then a professor at the University of California, Berkeley. Weyl consulted with Chern, who agreed that "they [Zhu and Chao] are legitimate as long as we recognize the Nationalist Government in Formosa. . . . although I have always wished that the money could be spent on Chinese mathematics." Chern to Weyl, November 17, 1950, in DO/Fac/Weyl-Acad Sinica. 
had long ago returned the funds. ${ }^{149}$ In a pattern reminiscent of his first IAS visit in the 1940s, this dispute apparently did not diminish the welcome Hua received at the institute when he arrived in late 1980. It provided funding and extended his stay from the initially planned four weeks to six, with the strong support of Shing-Tung Yau 丘成 桐 (Qiu Chengtong), a prominent Chinese American mathematician who had received his PhD under Chern at Berkeley in 1971 and who was then a professor in mathematics at the IAS. 150

For his part, Chern remained highly productive in his mathematical research and teaching in the US, emerging as one of the most influential mathematicians in the world. He was recognized with the US National Medal of Science in 1975 and the Wolf Prize in 1983. Twice he was welcomed back to the IAS as a visitor, one year in 1954-1955 and half a year in 1964-1965.151 He moved from Chicago to the University of California, Berkeley, in 1960, and became the founding director of its Mathematical Sciences Research Institute, sponsored by the US National Science Foundation, in the early 1980s. ${ }^{152}$ Hua and Chern met again in 1972 in Beijing during Chern's first visit back to China after he left in 1948 (Figure 7). Hua stayed at the Cherns' home in Berkeley for two days during his

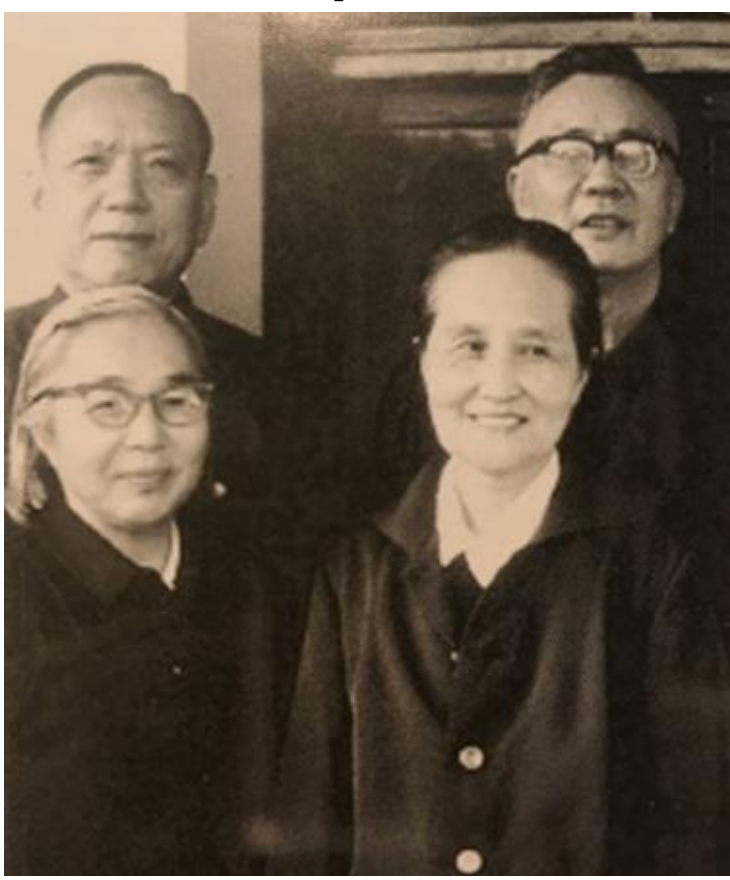

Figure 7: The Cherns and Huas meeting in Beijing in 1972. From left: Shih-Ning Cheng, Shiing-shen Chern, $\mathrm{Wu}$ Xiaoyuan, and Hua Luogeng (Chern 2002a). 1980-1981 visit to the US (Figure 8).

Three years later, Hua returned to the US for a final visit in 1983-1984, which lasted for nine months and was centered around the California Institute of Technology in Pasadena; Chern drove from Berkeley to see him (Chern 2001). Hua died in 1985 during a visit to Japan, while Chern moved permanently back to China in 2000 and lived on the campus of Nankai, his undergraduate alma mater in Tianjin. There he founded his third mathematical institute, which, like the first two, was likely influenced by what he

149 See correspondence in 1980 in DO/Fac/Weyl-Acad Sinica.

150 Harry Woolf (IAS director) to Hua, January 30, 1980; Hua to Woolf, February 20, 1980; S. T. Yau to IAS Mathematics Faculty, November 4, 1980; Woolf to Hua, November 11, 1980, all in Hua/DO/Mem.

151 See correspondence between Chern and IAS in this period in Chern/SM/MVA I.

152 Zhang and Wang 2011. See also, for example, Yau 2012, and Griffith 2006. 
experienced at the IAS. 153 The Nankai institute was renamed "The Chern Institute" after his death in 2004 (Wang 1999a, 1-8; Zhang and Wang 2011).

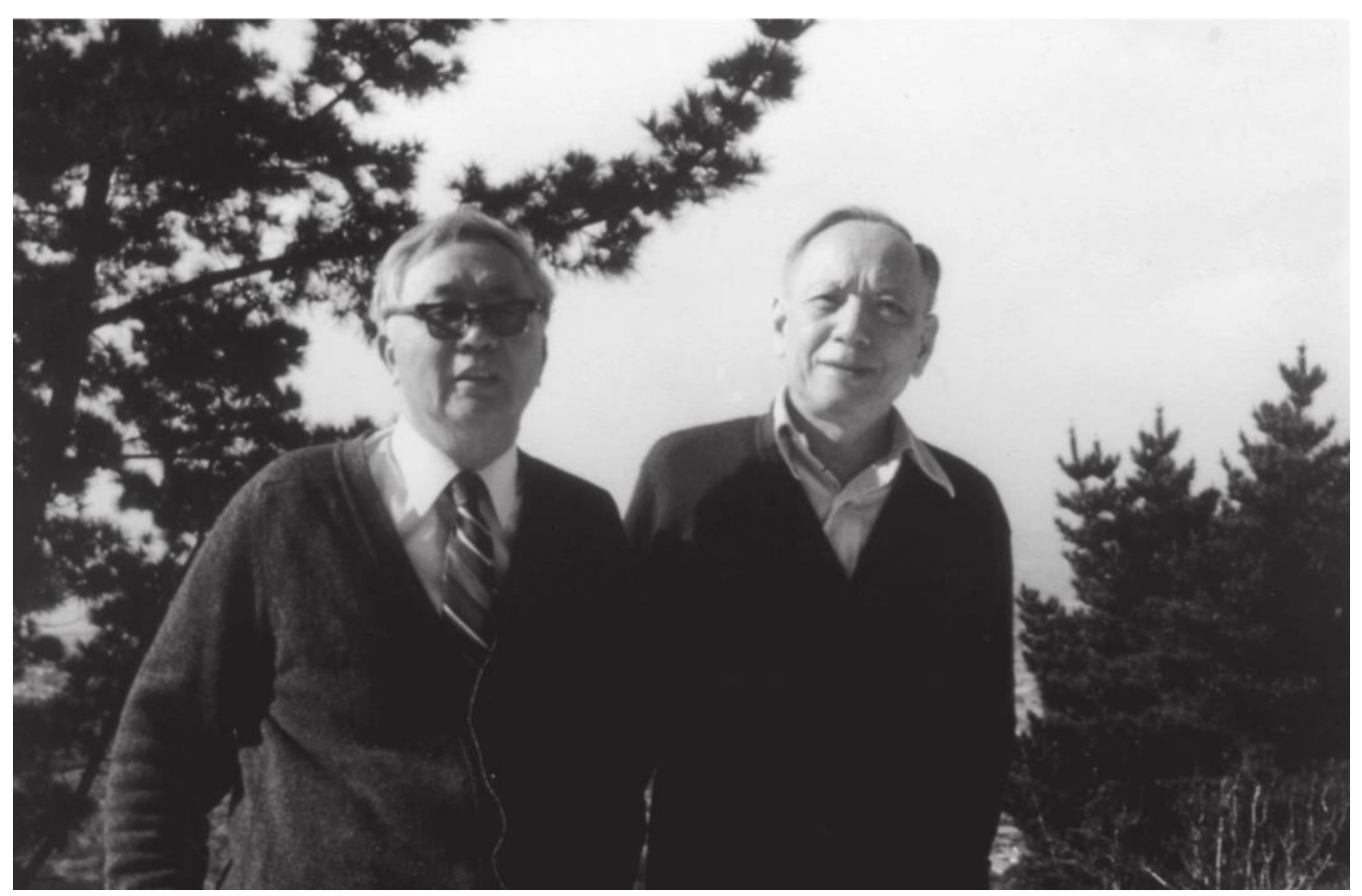

Figure 8: Hua Luogeng (left) and S. S. Chern (right) in the US in 1981 (Qiu, Yang, and Ji 2010, 7).

\section{Conclusions}

The human motivations behind various choices and actions are notoriously difficult to analyze, an issue that has inspired countless works of art. The play Copenhagen, for instance, suggests that we may never fully know what drives us to act, even at critical moments in our lives (Frayn 2000). ${ }^{154}$ From this historical study of Chern's and Hua's China-US transnational movements between 1943-1950, which centers on their mathematical research visits at the IAS in Princeton, we can at least conclude that it is important to explore both the macro socio-political aspects and the micro personal-professional ones to understand their motivations and choices in moving one

153 In a 1987 talk delivered in Taiwan, Chern reminisced about his experiences at the IAS and commented, "I believe that there is no other way to set up a research institution [than that of the IAS], i.e. to gather the greatest mathematicians, scientists [to work there]" (我想任何一个研究机关 能够成立的话没有第二条路子, 就是要有伟大的数学家、科学家) (Chern 2002b, 38).

154 It focused on the differing perspectives of the German physicist Werner Heisenberg and his Danish mentor Niels Bohr regarding their famous 1943 meeting in Copenhagen. 
direction or another. ${ }^{155}$ Chern's 1943 trip from Kunming to Princeton seemed to be mainly motivated by a professional desire to advance his own mathematical research, but both he and Veblen also framed it more broadly as a way for the US to assist Chinese scientific development. Hua cited his patriotic war work as the main cause for his inability to make the same trip in this period, but we now know that personal considerations, including his unwillingness to be in the shadow of Siegel, also influenced his decision. When Chern decided to return to the US in 1948-1949, it was not an accidental move triggered by Oppenheimer's telegram and based solely on professional considerations; it was a conscious act of geopolitical choice in the context of both the Chinese civil war and the early Cold War. Likewise, when Hua moved in the opposite direction, from the US back to China, in 1950, his motivations likely had both socio-political components-for example, support for the Chinese Communist Party and resentment of American racism - and personal-professional ones, including family considerations and perhaps his professional rivalry with Chern.

Regardless of their motivations, it is undeniable that Chern's and Hua's extended and fruitful visits at the IAS in this period helped reshape mathematics and possibly other scientific fields in China, as well as making great contribution to mathematics in the US. The substantive and even brilliant mathematical discoveries both made during their IAS visits and their far-reaching impact back in China certainly justified the arguments they made in their letters to Veblen and Weyl that such visits would help enhance their own scientific development and that of China generally. But the reverse was also true, as Weyl, Veblen, and others at the IAS and beyond came to realize: Chern and Hua, as temporary immigrant scientists-at least initially in Chern's case-made fundamental contributions to American mathematics, science, and education (Freeman 2017). They published their breakthroughs in American scientific journals and presented their cutting-edge research at lectures in American universities. At least in the case of Chern, he helped facilitate European-American scientific exchange by explaining Cartan's ideas to American colleagues. Finally, not to be underestimated were their roles in teaching, training, and mentoring young American scientists through their university lectures and collaborations.

Thus, this case study provides fresh evidence that immigration and, more generally, transnational scientific interactions, influenced as they are by a variety of factors, form a vital part of the process that brought American science to the world's leading edge and that keeps it in that position. ${ }^{156}$ In the cases of Chern and Hua, their transnational movements were both framed by geopolitical events, such as World War II and the Cold War, and affected by professional/institutional dynamics, such as their

155 On the complexity of transnational mathematical exchanges, see, for example, Tatarchenko and Phillips 2016, and Barany 2016.

156 See, for example, Krige 2019. 
interactions with Veblen, Weyl, and other mathematicians at the IAS in the 1940s. While Chern and Hua made personal, professional, and political choices in this pivotal period, they also created new mathematical knowledge that had a major impact on China and the US in the twentieth century and beyond.

\section{Acknowledgments}

We thank Erica Mosner of the Shelby White and Leon Levy Archives Center of the Institute for Advanced Study, Princeton, for excellent, courteous, and professional assistance and support. We also thank Professor Wang Yuan of the Chinese Academy of Sciences for kindly answering our questions; two anonymous reviewers and Professor Tian Miao 田炎水 for insightful and helpful suggestions; copy editor Charlie Zaharoff for improving the manuscript in many ways; Linda Stahnke Stepp of the University of Illinois Archives for assistance with archival materials; Professor Zhang Baichun 张柏春 and other colleagues at the Institute for the History of Natural Sciences of the Chinese Academy of Sciences in Beijing for hosting the workshop on this special issue of the Chinese Annals of History of Science and Technology in July 2019, when this paper was first presented; Professor Danian $\mathrm{Hu}$ 胡大年, the organizer of the workshop and this issue, and other workshop participants for stimulating discussions and helpful feedback.

\section{References}

Barany, Michael J. 2016. "Fellow Travelers and Traveling Fellows: The Intercontinental Shaping of Modern Mathematics in Mid-Twentieth Century Latin America." Historical Studies in the Natural Sciences 46 (5): 669-709.

Board of Trustees. 1950. Board of Trustees Minutes. Accessed November 2019. http://uihistories. library.illinois.edu/cgi-bin/rview_browsepdf?REPOSID=8\&ID=8141\&pagenum=572.

Cao, Zongxun 曹宗巽. 1999. “Guiqu laixi” 归去来兮 [Returning home]. In Jianguo chuqi liuxuesheng guiguo jishi 建国初期留学生归国纪事 [Accounts of students returning from abroad in the early years of the People's Republic of China], edited by National Committee of the CPPCC and Subcommittee of Cultural and Historical Data in Beijing, Shanghai, Tianjin, and Fujian 全国政协暨北京、上海、天津、福建政协文史资料委员会. Beijing: Chinese Literature and History Press.

Cartan, E. 1936. "Sur les domaines bornés homogenes de l'espace de $n$ variables complexes." Abhandlungen aus dem Mathematisehen Seminar der Hansischen Universität 11: 116-162.

Chern, Shiing-shen 1944a. "Integral Formulas for the Characteristic Classes of Sphere Bundles." Proceedings of the National Academy of Sciences 30 (9): 269-273.

Chern, Shiing-shen. 1944b. "A Simple Intrinsic Proof of the Gauss-Bonnet Formula for Closed Riemannian Manifolds." Annals of Mathematics 45 (4): 747-752.

Chern, Shiing-shen. 1964. “Xuesuan sishinian” 學算四十年 [Learning mathematics for forty 
years]. Zhuanji wenxue 傳記文學 [Biographical literature] 5 (5): 4-7.

Chern, Shiing-shen. [1988] 1989. “Zhongyang yanjiuyuan sannian” 中央研究院三年 [Three years at the Academia Sinica]. Zhongguo keji shiliao 中国科技史料 [China Historical Materials of Science and Technology] 9 (4). Reprinted in Chen Xingshen wenxuan 陈省身文选 [Selected papers of S. S. Chern] 16-19. Beijing: Science Press.

Chern, Shiing-shen. 1996. "My Mathematical Education." In A Mathematician and His Mathematical Work: Selected Papers of S S Chern, edited by S. Y. Cheng, P. Li, and G. Tian, 46-60. Singapore: World Scientific Publishing Company.

Chern, Shiing-shen. 2001. “Wo yu Hua Luogeng” 我与华罗庚 [Hua Luogeng and I]. Guangming ribao 光明日报 [Guangming Daily], March 26, 2001.

Chern, Shiing-shen. 2002a. Chen Xingshen wenji 陈省身文集 [Collected papers of S. S. Chern], edited by Zhang Dianzhou 张奠宙 and Wang Shanping 王善平. Shanghai: Eastern China Normal University Press.

Chern, Shiing-shen. 2002b. “Wo de ruogan shuxue shengya" 我的若干数学生涯 [My several mathematical lives]. In Chen Xingshen wenji, edited by Zhang Dianzhou and Wang Shanping, 34-39. Shanghai: Eastern China Normal University Press.

Chern, Shiing-shen. 2002c. “Xuesuan liushinian” 学算六十年 [Learning mathematics for sixty years]. In Chen Xingshen wenji, edited by Zhang Dianzhou and Wang Shanping. Shanghai: Eastern China Normal University Press.

Chern, Shiing-shen. 2002d. "Zhongyang yanjiuyuan sannian" 中央研究院三年 [Three years at the Academia Sinica]. In Chen Xingshen wenji, edited by Zhang Dianzhou and Wang Shanping, 12-14. Shanghai: Eastern China Normal University Press.

Csicsery, George Paul, dir. 2010. Taking the Long View: The Life of Shiing-shen Chern (a documentary). Berkeley, CA: Mathematical Sciences Research Institute.

Frayn, Michael. 2000. Copenhagen. New York: Anchor Books.

Freeman, Richard. 2017. "Migration of Ideas: China and U.S." Science 356 (6339): 696-697.

Griffith, Philip, ed. 2006. Inspired by S. S. Chern: A Memorial Volume in Honor of a Great Mathematician. Singapore: World Scientific.

Guo, Jinhai. 2006. “Chen Xingshen zai Zhongyang yanjiuyuan shuxue yanjiusuo” 陈省身在中央 研究院数学研究所 [Chern at the Institute of Mathematics of the Academia Sinica]. Ziran kexueshi yanjiu 自然科学史研究 [Studies in the History of Natural Sciences] 25 (4): 398-409

Guo, Jinhai. 2019. Xiandai shuxue zai Zhongguo de dianji 现代数学在中国的奠基 [The founding of modern mathematics in China]. Guangzhou: Guangdong People's Press.

Halberstam, Heini. 2004. “Loo-Keng Hua." Accessed June 9, 2019. http://mathshistory.standrews.ac.uk/Biographies/Hua.html.

Hsiung, C. C. 2001. "Personal and Professional History." In Selected Papers of Chuan-Chih Hsiung Singapore: World Scientific.

Hua, Luogeng. [1949] 2009. “Hua to Xu Lizhi, September 9, 1949." Reprinted in Xu Lizhi fangtan $l u$ 徐利治访谈录 [Interviews with Xu Lizhi], edited by Xu Lizhi 徐利治, Yuan Xiangdong 袁向 东, and Guo Jinhai, 242-243. Changsha: Hunan Education Press.

Hua, Luogeng. 1953. “Fang Su tihui diandi” 访苏体会点滴 [Reflections from a visit to the Soviet Union]. Renmin ribao 人民日报 [People's Daily], October 11, 1953, 3.

Hudeček, Jiři. 2017. "Hua Loo-Keng's Popularization of Mathematics and the Cultural 
Revolution." Endeavour 41 (3): 85-93.

Jackson, Allyn. 1998. "Interview with Shiing Shen Chern." Notices of the AMS 45 (7): 860-865.

Krige, John, ed. 2019. How Knowledge Moves: Writing the Transnational History of Science and Technology. Chicago: University of Chicago Press.

Krige, John, and Kai-Henrik Barth, eds. 2006. Global Power Knowledge: Science and Technology in International Affairs. In Osiris, vol. 21. Chicago: University of Chicago Press.

Krige, John, and Kai-Henrik Barth, eds. 2006. Global Power Knowledge: Science and Technology in International Affairs. Chicago: University of Chicago Press.

Li, Yuanping 李元平. 1992. Yu Dawei zhuan 俞大維傳 [A biography of Yu Dawei]. Taipei: Taiwan Daily Press.

Neushul, Peter, and Zuoyue Wang. 2000. "Between the Devil and the Deep Sea: C. K. Tseng, Mariculture, and the Politics of Science in Modern China." Isis 91 (1): 59-88.

Palais, Richard S., and Chuu-Lian Terng. 1996. "The Life and Mathematics of Shiing-shen Chern." In A Mathematician and His Mathematical Work: Selected Papers of S S Chern, edited by S. Y. Cheng, P. Li, and G. Tian, 1-45. Singapore: World Scientific Publishing Company.

Qian, Chengjun 钱承军. 2017. “Yi fuqin Qian Wen tan Hua Luogeng” 忆父亲钱闻谈华罗庚 [Recollections of interviews with my father about Hua Luogeng]. Zhongshan fengyu 钟山风雨 [Winds and rains over Zhong mountain] (2): 41-43.

Qiu, Cheng tong 丘成桐, Yang Le 杨乐, and Ji Lizhen 季理真, eds. 2010. Chuanqi shuxuejia Hua Luogeng: Jinian Hua Luogeng danchen 100 zhounian 传奇数学家华罗庚: 纪念华罗庚诞辰 100 周年 [Legendary mathematician Hua Luogeng: Commemorating the 100th birthday of Hua Luogeng]. Beijing: Higher Education Press.

Research Office on the History of Tsinghua University 清华大学校史研究室, ed. 1994. Qinghua Daxue shiliao xuanbian 清华大学史料选编 [Selected materials related to the history of Tsinghua University] vol. 3, part 1, 307-316. Beijing: Tsinghua University Press.

Richard, Jean W. 2010. "Hua Loo-Keng and the Movement of Popularizing Mathematics in the People's Republic of China." Journal of Mathematics Education at Teachers College 1 (Fall-Winter): 22-27.

Rider, Robin E. 1984. "Alarm and Opportunity: Emigration of Mathematicians and Physicists to Britain and the United States, 1933 - 1945." Historical Studies in the Physical Sciences 15 (1): 107 176.

Salaff, Stephen. 1972. “A Biography of Hua Lo-Keng.” Isis 63 (2): 142-183.

Siegel, Carl Ludwig. 1943. "Symplectic Geometry." American Journal of Mathematics 65 (1): 1-86.

Tatarchenko, Ksenia, and Christopher J. Phillips. 2016. “Mathematical Superpowers: The Politics of Universality in a Divided World." Historical Studies in the Natural Sciences 46 (6): 549-555.

Tian, Miao 田沝. 2000. “Chen Xingshen caifang lu” 陈省身采访录 [Interviews with Shiing-shen Chern]. Zhongguo kejishi zazhi 中国科技史杂志 [The Chinese Journal for The History of Science and Technology] 21 (2): 117-127.

Wang, Shiping 王士平, Li Yanping 李艳平, and Dai Nianzu 戴念祖. 2006. “20 shiji 40 niandai Jiang Jieshi he guomin zhengfu de yuanzidan zhi meng” 20 世纪 40 年代蒋介石和国民政府的原 子弹之梦 [The atomic bomb dream of Chiang Kai-shek and the Nationalist government in the 1940s]. Zhongguo kejishi zazhi 27 (3): 197-210.

Wang, Yuan. 1999a. Hua Loo-Keng, translated by Peter Shiu. Singapore: Springer-Verlag. 
Wang, Yuan. 1999b. Hua Luogeng 华罗庚. Nanchang: Jiangxi Education Press.

Wang, Zuoyue. 2002. "Saving China through Science: The Science Society of China, Scientific Nationalism, and Civil Society in Republican China." Osiris: A Research Journal Devoted to the History of Science and Its Cultural Influences 17: 291-322.

Wang, Zuoyue. 2010. "Transnational Science during the Cold War: The Case of Chinese/American Scientists." Isis 101: 367-377

Weil, André. 1996. "S. S. Chern as Geometer and Friend." In A Mathematician and His Mathematical Work: Selected Papers of S S Chern, edited by S. Y. Cheng, P. Li, and G. Tian, 72-75. Singapore: World Scientific Publishing Company.

Wu, Hung-Hsi 伍鸿熙 (Wu Hongxi). 2005. “Chen Xingshen de Bokeli suiyue” 陈省身的伯克利 岁月 [Shiing-shen Chern's Berkeley years]. In Jinian Chen Xingshen xiansheng wenji 纪念陈省身 先生文集 [A collection of essays in memory of Shiing-shen Chern], edited by Shing-Tung Yau, Liu Kefeng 刘克峰, and Ji Lizhen, 92-101. Hangzhou: Zhejiang University Press.

Wu, Hung-Hsi. 2007. “Shiing-shen Chern." Proceedings of the American Philosophical Society 151 (1): 97-101.

Xu, Lizhi. 2010. “Zhunyi wo de daxue laoshi Hua Luogeng xiansheng” 追忆我的大学老师华罗庚 先生 [Remembering my university professor Mr. Hua Luogeng]. Gaodeng shuxue yanjiu 高等数 学研究 [Studies in College Mathematics] 13 (6): 2-5.

Xu, Lizhi, Yuan Xiangdong, and Guo Jinhai. 2009. Xu Lizhi fangtan lu 徐利治访谈录 [Interviews with Xu Lizhi]. Changsha: Hunan Education Press.

Xu, Yibao. 2002. “Chinese-U.S. Mathematical Relations, 1859-1949.” In Mathematics Unbound: The Evolution of an International Mathematical Research Community, 1800-1945, edited by Karen Hunger Parnshall and Adrian C. Rice, 287-310. Providence, RI: American Mathematical Society.

Xu, Zuzhe 徐祖哲. 2015. Suyuan Zhongguo jisuanji 溯源中国计算机 [Tracing the origins of computers in China]. Beijing: SDX Joint Publishing Company.

Yau, Shing-Tung, ed. 2012. S. S. Chern: A Great Geometer of the Twentieth Century. Boston: International Press.

Yuan, Xiangdong. 1995. “Hua Luogeng zhi Chen Lifu de san feng xin” 华罗庚致陈立夫的三封信 [Three letters from Hua Luogeng to Chen Lifu]. Zhongguo keji shiliao 16 (1): 60-67.

Zhang, Dianzhou, and Joseph W. Dauben. 1994. "Mathematical Exchanges between the United States and China: A Concise Overview (1850-1950)." In The History of Modern Mathematics, Volume III: Images, Ideas, and Communities, edited by Eberhard Knobloch and David E. Rowe, 262-297. Boston: Academic Press.

Zhang, Dianzhou, and Wang Shanping. 2011. Chen Xingshen zhuan 陈省身传 [A biography of S. S. Chern]. Tianjin: Nankai University Press.

Zhu, Kezhen 竺可桢. 2006. Zhu Kezhen quanji 竺可桢全集 [The Complete Works of Coching Chu] vol. 8. Shanghai: Shanghai Science and Technology Education Press. 